\title{
Screening of Cellulase-producing Bacteria and their Effect on the Chemical Composition and Aroma Quality Improvement of Cigar Wrapper Leaves
}

\author{
Lan Yao,, a,, 1 Daoyu Li, ${ }^{\mathrm{a}, 1}$ Chengyi Huang, ${ }^{\mathrm{a}}$ Yahao Mao, ${ }^{\mathrm{a}}$ Zhi Wang, ${ }^{\mathrm{a}}$ Jun Yu, ${ }^{\mathrm{c}, *}$ \\ Chunlei Yang, ${ }^{\mathrm{c}, *}$ and Xiong Chen ${ }^{\mathrm{a}, *}$
}

\begin{abstract}
A high yield cellulase production strain was screened from the surface of cigar wrapper leaves and added to cigar wrapper leaves for fermentation in the present study. The enzyme-producing strain was identified as Bacillus velezensis, and its maximum carboxymethyl cellulase activity could reach $44.3 \mathrm{U} / \mathrm{mL}$. Making the cellulose degradation rate of cigar wrapper leaves as the index, the fermentation temperature, inoculum concentration, and carbon and nitrogen source addition concentration were optimized by response surface methodology. The results showed that under the conditions of inoculation concentration of $20 \%$, fermentation temperature of $37{ }^{\circ} \mathrm{C}$, addition of $4.5 \%$ glucose and $2.25 \%$ glutamate, the highest degradation rate of tobacco cellulose was $31.7 \%$. Significance analysis results showed that the order of factors affecting the degradation rate of cigar wrapper cellulose was: inoculation concentration > carbon and nitrogen source addition concentration $>$ temperature. The analysis of aroma substances under the optimal conditions found that the total amount of aroma substances of cigar wrapper increased by $26.1 \%$ compared with that before fermentation, in which $\beta$-damascenone, megastigmatrienone, farnesyl acetone, and solanone were significantly improved. The results were conducive to improving the aroma quality and concentration of cigar wrapper leaves.
\end{abstract}

DOI: 10.15376/biores.17.1.1566-1590

Keywords: Bacillus velezensis; Cigar wrapper leaves; Cellulose; Central composite design

Contact information: a: Key Laboratory of Fermentation Engineering (Ministry of Education), College of Bioengineering, Hubei University of Technology, 28th of Nanli Road, Wuhan 430068, China;

b: Collaborative Grant-in-Aid of the HBUT National "111" Center for Cellular Regulation and Molecular Pharmaceutics, Hubei University of Technology, Wuhan 430068, China; c: Tobacco Research Institute of Hubei Province, Hubei Wuhan 430030, China; *Corresponding authors: cx163_qx@163.com

${ }^{1}$ The two authors contributed equally to this paper

\section{INTRODUCTION}

Cellulose is an important component of tobacco leaves. The content of cellulose in tobacco leaves is generally about $11 \%$ and increases with the decrease of tobacco grade (Yan et al. 2005). The content of cellulose not only has a great impact on the smoking quality of tobacco leaves, but it also affects the physical properties of tobacco leaves. It is found that high cellulose content in tobacco leaves will result in rough and broken tobacco tissues (Pu and Liu 2019).

Cellulose content is important for cigar wrapper, which is a special tobacco product. It is only used for the outer skin of the cigar. The integrity is an important factor determining the quality of cigar wrapper (Shi et al. 2006). The demands of cigar wrapper 
leaves with high quality include thin leaves, thin veins, strong toughness, and uniform color and luster. The thick veins of tobacco leaves and high cellulose content could lead to poor toughness and poor application of cigar leaves ( $\mathrm{Li}$ et al. 2022). Furthermore, when the cellulose content is too high, the tobacco tissue becomes rough and easy to break. Tobacco leaves would produce rough smoke after combustion with high cellulose content, which is easy to produce unpleasant smell (Pu et al. 2019).

Fermentation is an essential process to improve the qualities of tobacco by eliminating harmful odors, degrading harmful substances, reducing offensive odor, and producing tobacco-specific flavors (Yang et al. 2018a; Li et al. 2020a). Many studies have shown the important role of microbiology through the whole process of tobacco fermentation (Du et al. 2016; Zhou et al. 2018). In recent years, researchers have found that adding specific microorganisms during tobacco fermentation can greatly improve the smoking quality of tobacco. Yeast and Bacillus were applied in the process of solid-state fermentation of tobacco leaves. The results showed that the added microorganisms could decrease the contents of starch and protein, while increasing the contents of amino acids and petroleum ether extracts of tobacco leaves significantly (Wang et al. 2015). In another study, tobacco leaves were fermented with Bacillus amyloliquefaciens GUHP86 and GZU03. It was found that the relative content of aroma substances such as linalool, $\beta$ damascenone, and $\beta$-ionone in tobacco leaves were increased, indicating that microbial fermentation can significantly improve the quality of tobacco leaves (Shuai et al. 2020). Furthermore, it was found by Zhang et al. (2012) that Saccharomyces cerevisiae could double the aroma substances in the tobacco extract compared with the control, in which ketones, esters, alcohols and other aroma substances increased in various extents. After screening aroma producing Bacillus from tobacco leaves and applied in tobacco leaves fermentation, it was found that aroma components such as esters, aldehydes, and acids in tobacco leaves were significantly increased, in which acetoin accounted for more than $60 \%$ (Zeng et al. 2020).

The quality of tobacco leaves could be improved by reducing the content of cellulose in tobacco leaves (Wang et al. 2012). Li et al. (2020b) isolated a strain (Luteibacter sp.L43) from tobacco straw with high cellulase production ability. The enzyme activity was $16.9 \mathrm{U} / \mathrm{mL}$ and $39.62 \mathrm{U} / \mathrm{mL}$ for filter paper activity and exoglucanase activity, respectively. Cellulase activity produced by Bacillus pumilus isolated from tobacco reached $9.91 \mathrm{U} / \mathrm{mL}$ (Liu et al. 2015b). In addition, other researchers also found that Bacillus subtilis has the ability to produce cellulase (Liang et al. 2019; Li et al. 2019a; Wang et al. 2019). Crude enzyme from Trichoderma viride was used to treat tobacco leaves by Chen et al. (2015). It was shown that with the increase of crude enzyme solution concentration, the degradation rate of cellulose in tobacco leaves increased, and the total sugar content was increased accordingly, which was brought about by the degradation of cellulose (Chen et al. 2015). Bacillus cereus fermented with cigar leaves showed that the contents of hemicellulose and cellulose were decreased by $6.63 \%$ and $8.19 \%$ respectively. The contents of phyllol alcohol, n-hexacosane, and other substances increased significantly (Li et al. 2022). But up until now, the application of cellulase production strain in quality improvement of cigar leaves has not been reported.

In this study, a strain with high cellulase production ability was isolated and screened from the surface of cigar wrapper leaves. Then, it was added to the fermentation process to explore the effect of the strain on the cellulose content and aroma components after fermentation. The fermentation process of tobacco leaves was optimized to provide a theoretical basis for industrial production to improve the quality of cigar wrapper leaves. 


\section{EXPERIMENTAL}

\section{Materials}

The cigar leaves were CX-014 after drying in Enshi Prefecture, Hubei Province, China. All the chemical reagents used in the study were purchased from Sinopharm group (Shanghai, China).

\section{Culture medium}

Bacterial isolation medium: beef extract $5.0 \mathrm{~g}$, peptone $10.0 \mathrm{~g}, \mathrm{NaCl} 5.0 \mathrm{~g}$, agar 20 $\mathrm{g}, \mathrm{pH} 7.0$ to 7.2 , deionized water $1000 \mathrm{~mL}$, ampicil $1 \%$, and sterilized at $121^{\circ} \mathrm{C}$ for 20 min.

Cellulase production screening medium: CMC-Na $10.0 \mathrm{~g}$, peptone $5.0 \mathrm{~g}$, yeast powder $5.0 \mathrm{~g}, \mathrm{KH}_{2} \mathrm{PO}_{4} 1.0 \mathrm{~g}, \mathrm{NaCl} 10 \mathrm{~g}$, agar $20.0 \mathrm{~g}$, deionized water $1000 \mathrm{~mL}, \mathrm{pH} 7.0$ to 7.2, $121{ }^{\circ} \mathrm{C}$, and sterilized at $121{ }^{\circ} \mathrm{C}$ for $20 \mathrm{~min}$.

LB medium: $10 \mathrm{~g}$ tryptone, $10 \mathrm{~g} \mathrm{NaCl}, 5 \mathrm{~g}$ yeast powder, $1000 \mathrm{~mL}$ deionized water, $\mathrm{pH}$ value 7.0 to 7.2 , and sterilization at $121{ }^{\circ} \mathrm{C}$ for $20 \mathrm{~min}$.

Cellulase producing medium: $10 \mathrm{~g}$ protein, $10 \mathrm{~g}$ yeast powder, $10 \mathrm{~g} \mathrm{CMC-Na,} 5 \mathrm{~g}$ $\mathrm{NaCl}, 1 \mathrm{~g} \mathrm{KH}_{2} \mathrm{PO}_{4}, 1000 \mathrm{~mL}$ deionized water, $\mathrm{pH}$ value 5.8 to 6.0, and sterilization at 121 ${ }^{\circ} \mathrm{C}$ for $20 \mathrm{~min}$.

\section{Methods}

Isolation of strains

First, $10 \mathrm{~g}$ cigar wrapper leaves were cut into pieces and mixed with $90 \mathrm{~mL}$ sterile $0.85 \%(\mathrm{w} / \mathrm{v}) \mathrm{NaCl}$ solution containing glass beads under sterile conditions. Then the mixture was shaken at $30^{\circ} \mathrm{C}$ at $200 \mathrm{r} / \mathrm{min}$ for $1 \mathrm{~h}$ to obtain microbial extract. Next, $1 \mathrm{~mL}$ of supernatant was taken out and diluted with sterile $0.85 \%(\mathrm{w} / \mathrm{v}) \mathrm{NaCl}$ solution to a concentration of $10^{-1}$ to $10^{-7}$. Then, $100 \mu \mathrm{L}$ of each concentration was spread on the bacterial isolation medium and incubated at $37{ }^{\circ} \mathrm{C}$ for $24 \mathrm{~h}$. Individual colonies with obvious morphological differences were selected and cultured individually. The purified strains were stored in the refrigerator at $4{ }^{\circ} \mathrm{C}$.

\section{Screening of cellulase producing strains}

The above preserved strains were spot-plated on the cellulase production screening medium. After being cultured at $37{ }^{\circ} \mathrm{C}$ for $24 \mathrm{~h}$, they were flooded with $1 \mathrm{mg} / \mathrm{mL}$ Congo red solution for $30 \mathrm{~min}$, then rinsed with saline 3 to 5 times. Strains with the presence of halo zones around bacterial colonies were selected. The $D / d$ value was calculated based on the diameter of halo zones $(d)$ and colony diameter $(D)$.

\section{Cellulase activity determination}

The determination of cellulase activity refers to the work of Dong $(2011)$. At $50^{\circ} \mathrm{C}$, 1 unit of cellulase activity was defined as the amount of enzyme required to release $1 \mu \mathrm{g}$ glucose per min.

Protease activity was determined according to SB/T 10317-1999. At $40{ }^{\circ} \mathrm{C}, 1$ unit of protease activity was defined as the amount of enzyme required to release $1 \mu \mathrm{g}$ tyrosine per min from casein.

The $\alpha$-amylase activity was measured with reference to the work of Xiao et al. (2006). At $50^{\circ} \mathrm{C}$ and $\mathrm{pH} 7,1$ unit of amylase activity was defined as the amount of enzyme required to make the disappearance of $1 \mu \mathrm{g}$ starch per min, which was bound with iodine. 


\section{Identification of strains}

The DNA was extracted with the DNA extraction kit (Tiangen dp302, Tiangen, Beijing, China), which was used as the template. Additionally, 27F (5'- gagttgatcetgctcag3'), 1527r (5'- agaaggaggtgatccagcc-3') was used as primer for polymerase chain reaction (PCR) amplification of 16SrDNA gene sequence (Dai 2012). The amplification procedure was: pre-denaturation at $94{ }^{\circ} \mathrm{C}$ for $10 \mathrm{~min}$, denaturation at $94{ }^{\circ} \mathrm{C}$ for $30 \mathrm{~s}$, renaturation at $60{ }^{\circ} \mathrm{C}$ for $1 \mathrm{~min}$, extension at $72{ }^{\circ} \mathrm{C}$ for $1 \mathrm{~min}, 30$ cycles, and extension at $72{ }^{\circ} \mathrm{C}$ for $10 \mathrm{~min}$. The amplification product was detected by agarose gel electrophoresis. The sequencing results were compared on NCBI (Bethesda, MD, USA). The strain phylogenetic tree was constructed by Mega X64 software (Mega Software, Paris, France).

Table 1. PCR Amplification System

\begin{tabular}{|c|c|}
\hline Reagent & $\boldsymbol{\mu L}$ \\
\hline Premix Taq polymerase & 25 \\
\hline Upstream primer & 1 \\
\hline Downstream primer & 1 \\
\hline Template DNA & 1 \\
\hline Sterile water & 22 \\
\hline Total & 50 \\
\hline
\end{tabular}

\section{Fermentation method}

First, the cigar leaves were rewetted to the moisture content of $30 \% \pm 0.07 \%$. The bacteria cultured to the late logarithmic growth stage were mixed with a certain concentration of glucose and glutamate (added based on the weight of cigar wrapper leaves) to obtain the inoculum (Qin et al. 2020). The inoculum was evenly sprayed on the cigar wrapper leaves. After balancing the moisture for $2 \mathrm{~h}$, cigar leaves were put into a constant temperature and humidity incubator for fermentation. After fermentation, cigar leaves were dried at $40{ }^{\circ} \mathrm{C}$. All the experiments were done in triplicate, the standard deviation is shown in all figures.

Optimization of fermentation conditions by central composite design

Based on the preliminary results, fermentation temperature, inoculation concentration, and carbon and nitrogen source addition concentration were optimized by central composite design (CCD). The statistical analysis software "Statistica 10" (Statistica, Tulsa, OK, USA) and "SPSS 26" (SPSS, Chicago, IL, USA) were used for the experimental design and data analysis ( $p$-value analysis), respectively.

\section{Determination of chemical components and cellulose content of cigar leaves}

(1) Cigar leaves were prepared according to YC/T 31-1996 (1996).

(2) Water-soluble total sugar and reducing sugar were determined according to YC/T 159-2002 (2002).

(3) Total alkaloids were determined according to YC/T 160-2002 (2002).

(4) Total nitrogen was determined according to YC/T 161-2002 (2002).

(5) Cellulose content was determined by cellulose (CLL) content detection kit (Solarbio bc4285 100t96s, Solarbio, Beijing, China).

Simultaneous distillation extraction (SDE) - GC/MS determination of aroma components After removing the main vein, the cigar wrapper leaves were dried at $75^{\circ} \mathrm{C}$ for $3 \mathrm{~h}$, 
then Wiley-milled (screen size $<2 \mathrm{~mm}$ was used). Accurate $10 \mathrm{~g}$ tobacco samples were weighed and put into a $1000 \mathrm{~mL}$ round bottom flask. Then, $200 \mathrm{~mL}$ saturated $\mathrm{NaCl}$ and 60 $\mathrm{mL}$ dichloromethane were each added into a $100 \mathrm{~mL}$ round bottom flask, which were connected to each side of the SDE device respectively. The organic phase (dichloromethane) was heated with a $55^{\circ} \mathrm{C}$ water bath, and the aqueous phase was heated with a $160{ }^{\circ} \mathrm{C}$ oil bath. The reaction continued for $5 \mathrm{~h}$ after liquid-liquid stratification. The extract were collected and concentrated to $2 \mathrm{~mL}$ with a rotary evaporator. Lastly, $50 \mu \mathrm{L}$ $1.2028 \mathrm{mg} / \mathrm{mL}$ phenylethyl acetate was added as internal standard.

\section{GC/MS determination}

Gas chromatography mass spectrometry (Agilent Technologies 5975c, Agilent Company, Santa Clara, CA, USA) was used to detect volatile flavor components. Chromatography included HP-5MS capillary column $(30 \mathrm{~m} \times 0.25 \mathrm{~mm} \times 0.25 \mu \mathrm{m})$. Helium was used as a carrier gas (flow rate: $1.0 \mathrm{~mL} / \mathrm{min}$ ). The initial temperature was $40{ }^{\circ} \mathrm{C}$, which was maintained for $2 \mathrm{~min}$. A $2{ }^{\circ} \mathrm{C} / \mathrm{min}$ rate was then used to reach $200{ }^{\circ} \mathrm{C}$ maintained for $5 \mathrm{~min}$, and then a $10{ }^{\circ} \mathrm{C} / \mathrm{min}$ rate to reach $280{ }^{\circ} \mathrm{C}$. Mass spectrometry involved a transmission line temperature of $250{ }^{\circ} \mathrm{C}$, an ion source temperature of $230{ }^{\circ} \mathrm{C}$, the EI ionization mode, and electron energy of $70 \mathrm{eV}$.

\section{Statistical analysis}

The statistical analysis software "Statistica 10.0" (Statistica, Tulsa, OK, USA) and SPSS 26.0 software (SPSS, Chicago, IL, USA) were used for the experimental design and data analysis ( $p$-value analysis).

\section{RESULTS AND DISCUSSION}

\section{Isolation and Screening of Cellulase Producing Strain}

A total of 30 strains of bacteria were screened from cigar wrapper leaves. After being incubated in cellulase production screening medium and stained with Congo red solution, halo zones around bacterial colonies could be observed from 6 strains, named Y1, $\mathrm{Y} 2, \mathrm{Y} 3, \mathrm{Y} 4, \mathrm{C} 1$, and $\mathrm{C} 2$ respectively. The results are shown in Table 2, including the diameter of halo zones $(D)$, diameter of colonies $(d)$, and $D / d$ values of each strain. The $D / d$ value can indirectly reflect the ability of the strain to produce cellulase. It can be found in Table 2 that the maximum $D / d$ value was 3.4 from strain $\mathrm{C} 1$. The values $D / d$ of other strains were less than 2 . Therefore, strain $\mathrm{C} 1$ was selected for subsequent experiments of cellulase production and fermentation application of cigar wrapper leaves.

Table 2. Halo Zones Diameter $(D, \mathrm{~cm})$, Colony Diameter $(d, \mathrm{~cm})$, and $D / d$ Value

\begin{tabular}{|c|c|c|c|}
\hline Strain & $\boldsymbol{D}$ & $\boldsymbol{d}$ & $\boldsymbol{D} / \boldsymbol{d}$ \\
\hline $\mathrm{Y} 1$ & 1.3 & 0.8 & 1.6 \\
\hline $\mathrm{Y} 2$ & 1.7 & 1.1 & 1.5 \\
\hline $\mathrm{Y} 3$ & 1.4 & 0.8 & 1.8 \\
\hline $\mathrm{Y} 4$ & 1.1 & 0.9 & 1.2 \\
\hline $\mathrm{C} 1$ & 2.4 & 0.7 & 3.4 \\
\hline $\mathrm{C} 2$ & 1.4 & 0.9 & 1.6 \\
\hline
\end{tabular}

Cellulase production and determination from $\mathrm{Cl}$

Strain C1 was inoculated into LB seed medium. After growing to stable period, it 
was inoculated into cellulase-producing fermentation medium with initial optical density (OD) 0.1 , at $37{ }^{\circ} \mathrm{C}$, and $200 \mathrm{r} / \mathrm{min}$. The carboxymethyl cellulase activity was determined every $12 \mathrm{~h}$. The results are shown in Fig. 1. As shown in the figure, carboxymethyl cellulase activity began to be produced at the $12^{\text {th }} \mathrm{h}$ after inoculation of strain $\mathrm{C} 1$. It increased rapidly at 12 to $24 \mathrm{~h}$ and reached the maximum value of $44.3 \mathrm{U} / \mathrm{mL}$ at $24 \mathrm{~h}$, and then decreased and stabilized with the increase of time.

In recent years, cellulase-producing strains have been reported by many other scholars. Sinorhizobium meliloti 224 was cultured with tobacco waste as substrate by Buntić et al. (2019). It was found that carboxymethyl cellulase activity reached $1.62 \mathrm{U} / \mathrm{g}$ after 2 days. A high-yield cellulase fungus from the soil of Shennongjia, Hubei Province, China was screened by $\mathrm{Lu}$ et al. (2012). After optimization of enzyme production conditions, the maximum carboxymethyl cellulase activity reached $5.17 \mathrm{IU} / \mathrm{mL}$. It was indicated that the cellulase production ability of $\mathrm{C} 1$ was higher than most reported bacteria and could be applied in cigar wrapper fermentation.

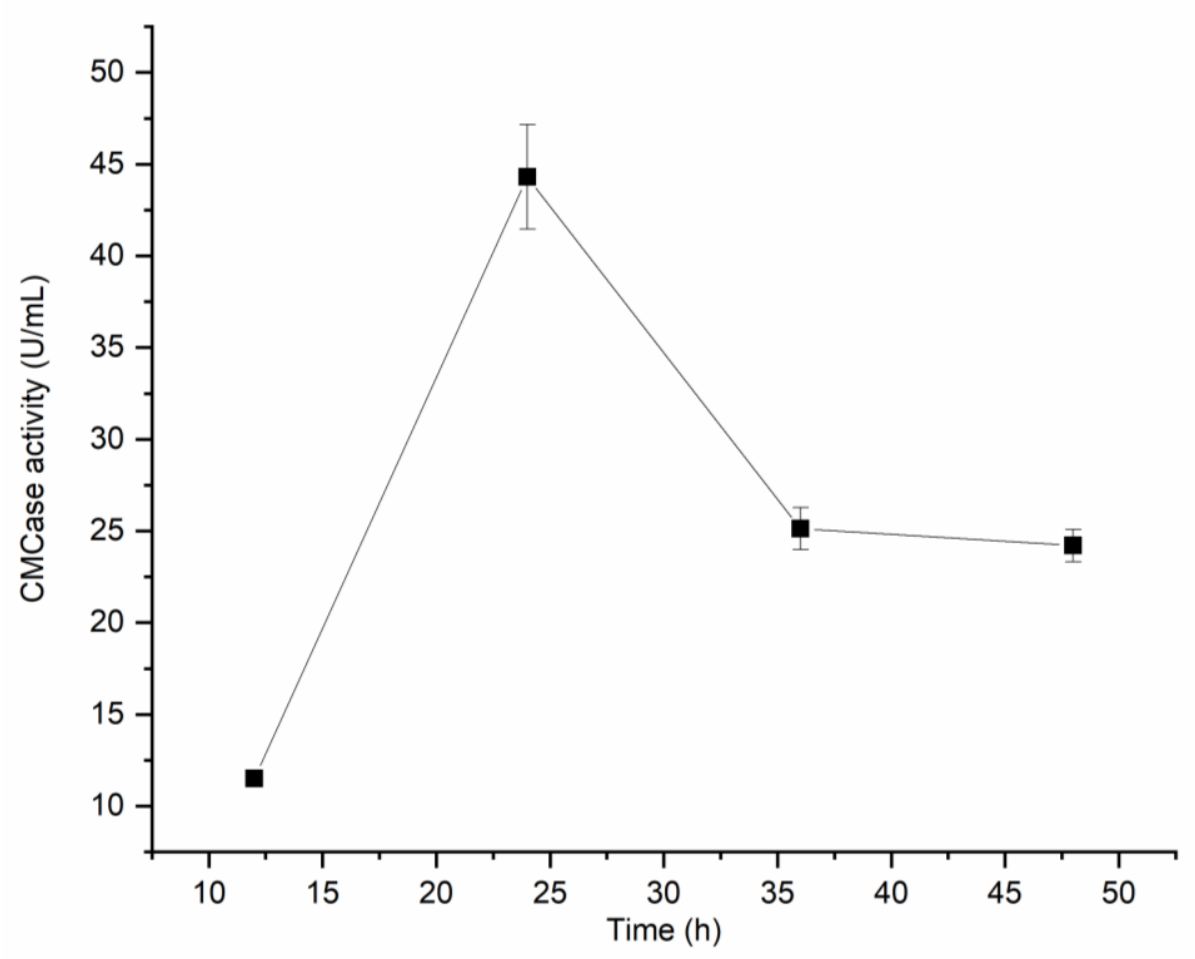

Fig. 1. Changes of carboxymethyl cellulase activity secreted by $\mathrm{C} 1$ with time

\section{Molecular identification of C1}

The genomic DNA of strain C1 was extracted and amplified by 16SrDNA. After electrophoretic detection, obvious bands could be observed near 1400bp (Fig. 2). Blast analysis of the sequencing results with known bacteria on NCBI showed that the strain had 99\% homology with Bacillus. Phylogenetic analysis (Fig. 3) showed that strain C1 was clustered with Bacillus velezensis in the genus Bacillus, and the strain was identified as Bacillus velezensis. 


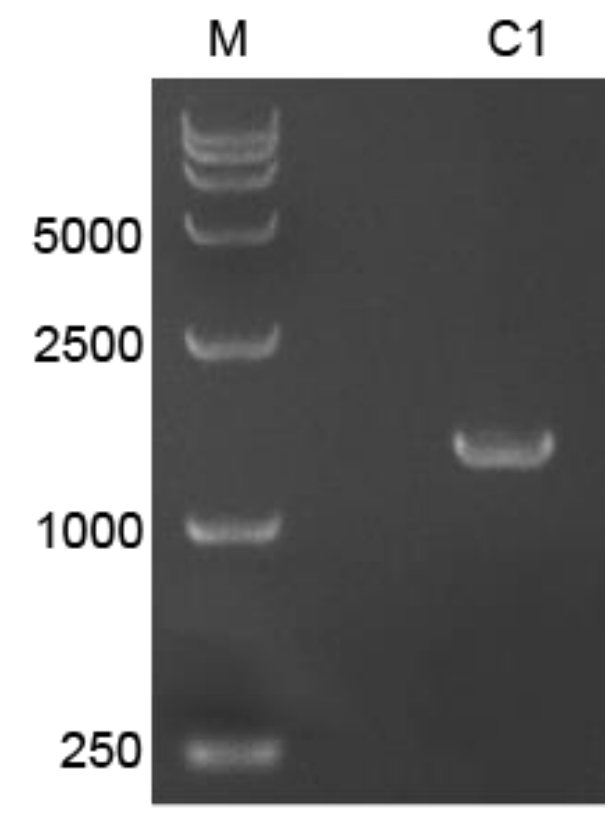

Fig. 2. Electrophoretic spectra of strain $\mathrm{C} 1$

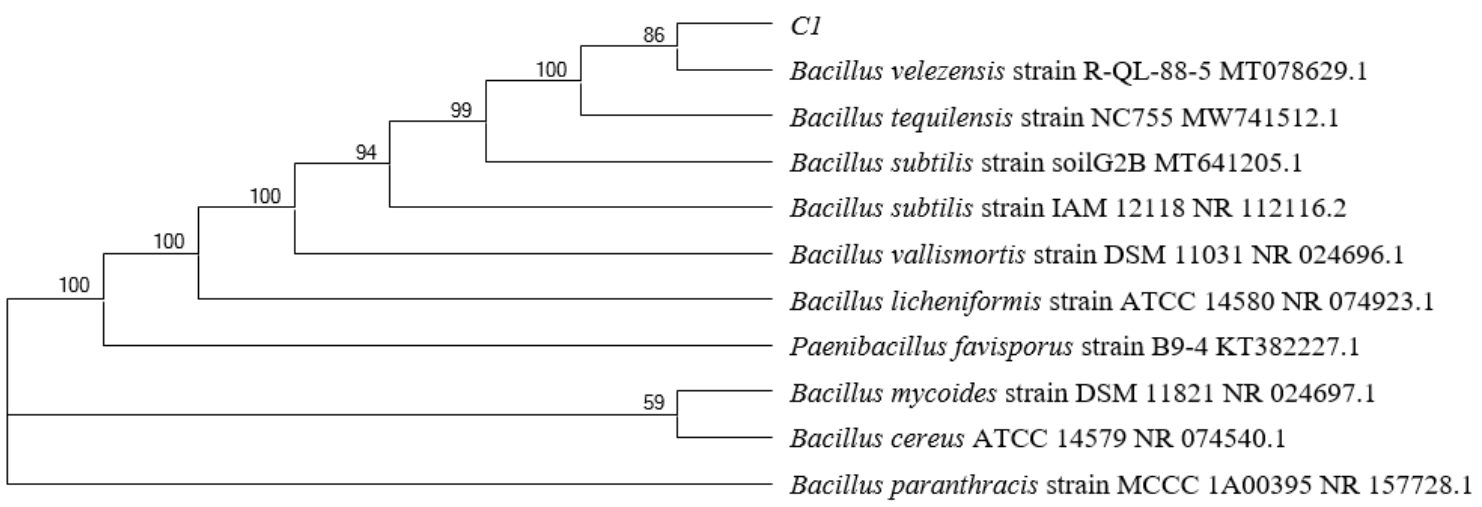

Fig. 3. Phylogenetic tree of 16 srDNA of strain $\mathrm{C} 1$

\section{Optimization of Fermentation Conditions by Central Combination Design- Response Surface Methodology}

Taking the degradation rate of cellulose in cigar wrapper as the response value, three factor and three-level experiments were designed based on the results of single factor experiment results (data not shown). The levels of variables are shown in Table 3 . The experimental design and results are shown in Table 4. The results indicated that trial 15 had the highest cellulose degradation rate among all trials. The percent of cellulose degradation reached $31.7 \%$, which was significantly higher than other trials. Figure 4 showed the response surface curves based on the results of Table 3.

From analysis results, shown in Table 4, it was found that apart from fermentation temperature, the other conditions were the same for the $13^{\text {th }}, 14^{\text {th }}$, and $15^{\text {th }}$ trials. It was suggested that with the increase of fermentation temperature, the cellulose degradation of cigar wrapper leaves increased first and then decreased. The cellulose degradation of cigar wrapper leaves reached the highest at $37{ }^{\circ} \mathrm{C}$, which was $31.7 \%$. It was shown that $37{ }^{\circ} \mathrm{C}$ was the optimum temperature of Bacillus velezensis to secret cellulase.

The fermentation conditions of the $9^{\text {th }}, 10^{\text {th }}$, and $15^{\text {th }}$ trials were the same except for 
inoculation concentration. The analysis results of the three trials showed that the degradation of cellulose increased first and then decreased with the increase of the inoculation concentration. When the inoculation concentration was $20 \%$, the degradation rate was increased by $57.7 \%$ (compared with 10\%) and $25.6 \%$ (compared with $30 \%$ ), respectively. It was indicated that the degradation rate of cellulose would not increase with the increase of the inoculation concentration. High inoculation concentration would result in fierce competition among strains, which is not beneficial to the consumption of cellulose in cigar wrapper leaves.

According to the analysis results of the $11^{\text {th }}, 12^{\text {th }}$, and $15^{\text {th }}$ trials, the degradation rate of cellulose was the highest with a glucose dose of $4.5 \%$. Compared with the glucose dose of $1.5 \%$ and $7.5 \%$, the degradation rate of cellulose was increased by $29.4 \%$ and $60.5 \%$ respectively. The results suggested that the degradation rate of cigar wrapper leaves cellulose was positively correlated with the addition amount of carbon source within a certain range. With the continuous increase of the addition amount of carbon source, the degradation rate of cellulose began to decline. Because when carbon source content is enough to meet the growth of the strain, there is no need for strains to secret cellulase to degrade cellulose.

The results showed that concentration of inoculation, fermentation temperature, and the addition of carbon and nitrogen sources could affect the growth of Bacillus velezensis $\mathrm{C} 1$, thus affecting the degradation of cellulose in cigar wrapper leaves. Cellulose has a great impact on the quality of cigar leaves. Research studies have shown that with the increase of cellulose content, the aroma quality and aftertaste of tobacco leaves become worse. Furthermore, the increased content of cellulose could result in decreased aroma amount, increased miscellaneous gas, increased irritation, and decreased overall sensory quality of tobacco leaves (Liu et al. 2015a). Cellulose in tobacco leaves is degraded into glucose by cellulase, and then glucose is transformed into aroma substances through different metabolic pathways by microorganisms. At present, some scholars have found that adding specific microorganisms in the process of tobacco fermentation can improve the quality of tobacco leaves. A strain of Bacillus pumilus producing cellulase was isolated from the surface of flue-cured tobacco and applied to increase the quality of tobacco leaves by Ni et al. (2012). It was found that the total sugar content in tobacco leaves was increased by $13.9 \%$ and that of reducing sugar was increased by $18.1 \%$. Bacillus subtilis was sprayed on tobacco leaves for fermentation by Wang et al. (2012). Results showed that the cellulose degradation rate of tobacco leaves reached $8.94 \%$ at the $168^{\text {th }} \mathrm{h}$, and the total soluble sugar content of fermented tobacco leaves increased by 7.66\%. A strain (Pseudomonas) that can degrade starch, cellulose, lignin, protein, and pectin at the same time was screened from tobacco leaves (Yu et al. 2021). After being applied in the fermentation of tobacco leaves, the pectin degradation was the most significant, more than $30 \%$, followed by cellulose (20\%). The degradation efficiency of starch and lignin was slightly weak, about $10 \%$. The content of total sugar in fermented tobacco leaves increased significantly. The analysis of the quality of fermented tobacco leaves showed that ketones, esters, and alcohols in tobacco leaves increased in various degrees. A strain of Bacillus subtilis producing cellulase was isolated from the surface of tobacco (Yang et al. 2018b), and the cellulase activity reached up to $6.6 \mathrm{U} / \mathrm{mL}$. When applied to the surface of tobacco leaves, the cellulose degradation rate was $30.6 \%$, which was similar to the current study. In this study, the highest degradation rate of tobacco cellulose reached $31.7 \%$, indicating that the degradation of tobacco cellulose by Bacillus velezensis $\mathrm{C} 1$ reached a medium and upper level in the current study. 
Table 3. Variables and Levels in the Central Composite Design

\begin{tabular}{|c|c|c|c|c|c|}
\hline & \multirow{2}{*}{ Variable } & \multirow{2}{*}{ Unit } & \multicolumn{3}{|c|}{ Coded Level } \\
\cline { 4 - 6 } & Temperature & & -1 & 0 & +1 \\
\hline A & Inoculation volume & ${ }^{\circ}$ C & 30 & 37 & 44 \\
\hline B & Glucose addition amount & $\%$ & 10 & 20 & 30 \\
\hline C & & $\%$ & 1.5 & 4.5 & 7.5 \\
\hline
\end{tabular}

Table 4. Central Composite Design and Results

\begin{tabular}{|c|c|c|c|c|c|}
\hline & $\begin{array}{c}\text { Temperature } \\
\left({ }^{\circ} \mathbf{C}\right)\end{array}$ & $\begin{array}{c}\text { Inoculation } \\
\text { Volume (\%) }\end{array}$ & $\begin{array}{c}\text { Glucose } \\
\text { Content (\%) }\end{array}$ & $\begin{array}{c}\text { Glutamic } \\
\text { Acid (\%) }\end{array}$ & $\begin{array}{c}\text { Cellulose } \\
\text { Degradation Rate } \\
(\%)\end{array}$ \\
\hline $\mathbf{1}$ & 30 & 10 & 1.5 & 0.75 & 4.67 \\
\hline $\mathbf{2}$ & 30 & 30 & 1.5 & 0.75 & 14.74 \\
\hline $\mathbf{3}$ & 30 & 10 & 7.5 & 3.75 & 14.24 \\
\hline $\mathbf{4}$ & 30 & 30 & 7.5 & 3.75 & 2.86 \\
\hline $\mathbf{5}$ & 44 & 10 & 1.5 & 0.75 & 4.01 \\
\hline $\mathbf{6}$ & 44 & 30 & 1.5 & 0.75 & 20.96 \\
\hline $\mathbf{7}$ & 44 & 10 & 7.5 & 3.75 & 3.72 \\
\hline $\mathbf{8}$ & 44 & 30 & 7.5 & 3.75 & 21.42 \\
\hline $\mathbf{9}$ & 37 & 10 & 4.5 & 2.25 & 20.09 \\
\hline $\mathbf{1 0}$ & 37 & 30 & 4.5 & 2.25 & 25.23 \\
\hline $\mathbf{1 1}$ & 37 & 20 & 1.5 & 0.75 & 24.48 \\
\hline $\mathbf{1 2}$ & 37 & 20 & 7.5 & 3.75 & 19.74 \\
\hline $\mathbf{1 3}$ & 30 & 20 & 4.5 & 2.25 & 25.20 \\
\hline $\mathbf{1 4}$ & 44 & 20 & 4.5 & 2.25 & 20.96 \\
\hline $\mathbf{1 5}$ & 37 & 20 & 4.5 & 2.25 & 31.69 \\
\hline
\end{tabular}

Table 5. Variance Analysis

\begin{tabular}{|c|c|c|c|c|}
\hline & df & Mean square & $\mathbf{F}$ & P \\
\hline Model & 14 & 252.804 & 23.745 & 0.0001 \\
\hline $\mathbf{B}$ & 1 & 10386.820 & 975.609 & 0.0001 \\
\hline $\mathbf{C}$ & 2 & 273.989 & 25.735 & 0.0006 \\
\hline $\mathbf{A}$ & 2 & 102.590 & 9.636 & 0.0024 \\
\hline $\mathbf{B}^{*} \mathbf{C}$ & 2 & 79.029 & 7.423 & 0.0005 \\
\hline $\mathbf{A}^{*} \mathbf{B}$ & 1 & 162.417 & 15.255 & 0.0001 \\
\hline $\mathbf{A}^{*} \mathbf{C}$ & 1 & 481.005 & 45.180 & 0.6245 \\
\hline $\mathbf{A}^{*} \mathbf{B}^{*} \mathbf{C}$ & 1 & 2.605 & 0.245 & 0.0003 \\
\hline Error & 30 & 10.646 & - & - \\
\hline Total & 45 & - & - & - \\
\hline
\end{tabular}

The variance analysis of three factors on the degradation rate of cellulose is shown in Table 5. According to the analysis results, the regression of the model was very significant $(\mathrm{P}<0.01, \mathrm{R} 2=0.917)$, indicating that the linear relationship between dependent variable and independent variable was significant. Comparing the F-value of each factor, the order of factors affecting the degradation rate of cellulose was: inoculation concentration > carbon and nitrogen source addition amount > fermentation temperature. According to the results, the three single factors and the interaction of the three factors showed a significant effect on the cellulose degradation rate of cellulose $(\mathrm{P}<0.01)$. It was suggested that the interaction between inoculation concentration and fermentation temperature had very a significant effect on the degradation rate of cellulose $(\mathrm{P}<0.01)$. The interaction between carbon and nitrogen source addition and inoculation concentration 
had a very significant effect on the degradation rate of cellulose $(\mathrm{P}<0.01)$. The interaction between carbon and nitrogen source addition and fermentation temperature had no significant effect on the degradation rate of cellulose in cigar wrapper leaves $(\mathrm{P}>0.05)$.

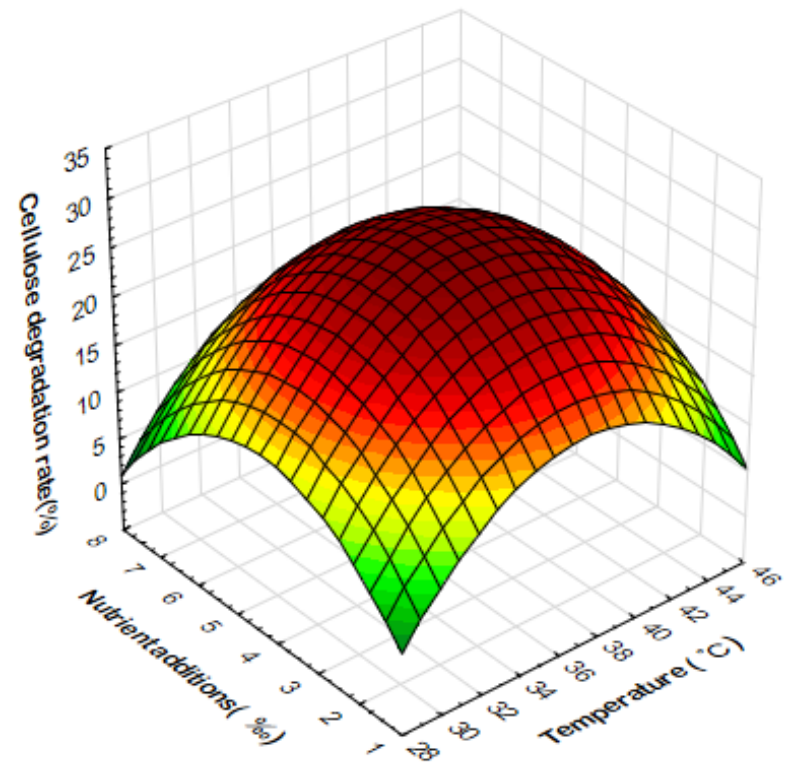

A.

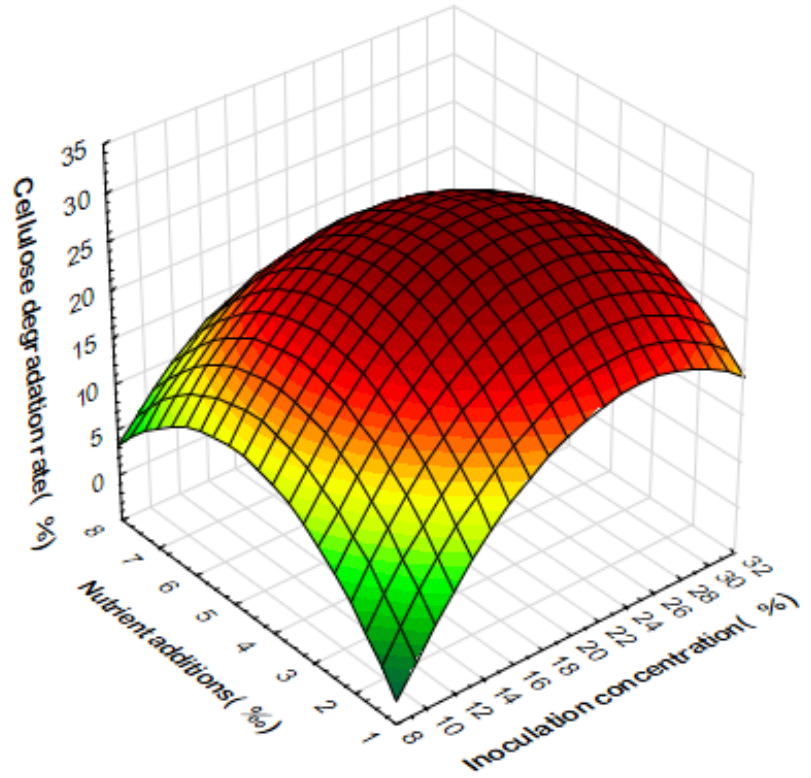

B.

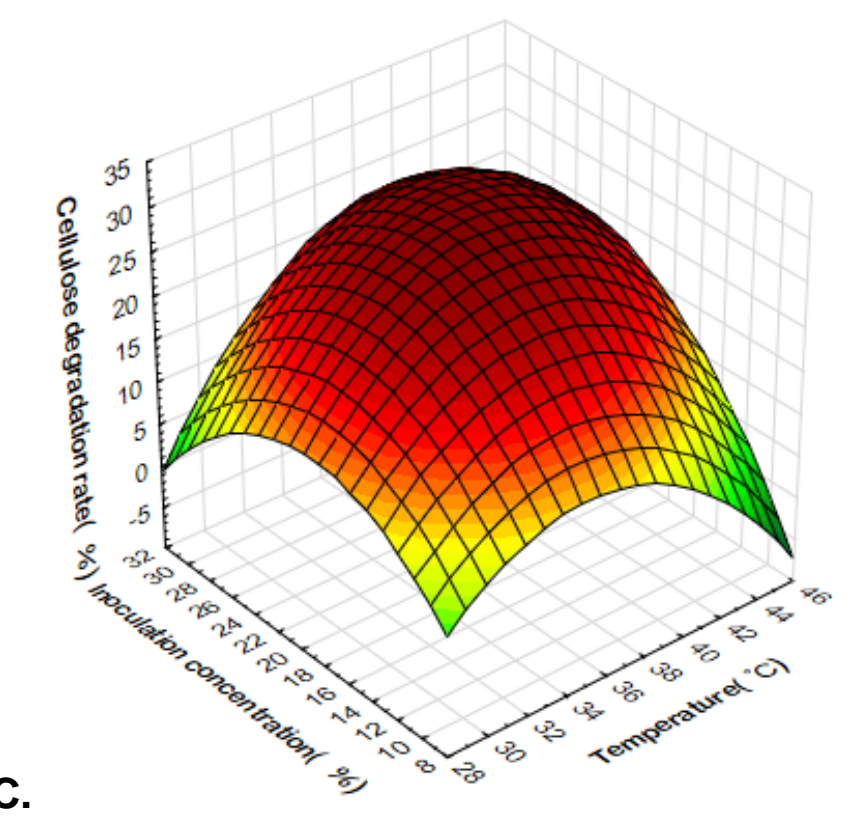

Fig. 4. Response surface curve representing the interactive effect of inoculation concentration, temperature and carbon source addition on cellulose degradation rate of cellulose: $(A)$ inoculation concentration and temperature; (B) effect of nutrient addition and inoculation concentration; and (C) effect of nutrient addition and temperature 


\section{Effect of Bacillus velezensis C1 on Properties of Cigar Wrapper Leaves}

Chemical composition

In order to study the effect of Bacillus velezensis $\mathrm{C} 1$ on the chemical composition of cigar wrapper leaves during the fermentation process, the changes of chemical composition of cigar wrapper leaves under the optimal fermentation conditions were compared with the controls. The results are shown in Fig. 5. The changes of reducing sugar are shown in Fig. 5A. It was found that the content of reducing sugar in control 1 and 3 was low before fermentation. With the progress of fermentation, the content of reducing sugar first increased, reached the maximum value of $0.13 \%$ and $0.14 \%$ respectively on the $2^{\text {nd }}$ day, and then started to decrease to $0.09 \%$ on the $6^{\text {th }}$ day. This may have been caused by the microbial degradation of starch, cellulose, and other substances in cigar wrapper leaves, producing reducing sugar in the early stage of fermentation. In the later stage of fermentation, the reducing sugar content of cigar wrapper leaves begins to decrease due to the needs of large numbers of microorganisms (Yao 2017). The content of reducing sugar in control 2 and treatment 4 was higher before fermentation, mainly due to the added glucose. With the progress of fermentation, the content of reducing sugar in control 2 decreased and tended to be stable after 4 days of fermentation. The content of reducing sugar at the end of fermentation was $0.26 \%$, while the content of reducing sugar in treatment 4 showed a downward trend in the whole fermentation process, which was $0.11 \%$ on the $6^{\text {th }}$ day.

The growth of primary microorganisms on the surface of cigar wrapper leaves consumed a lot of reducing sugar, which greatly reduced the content of reducing sugar in control 2. After 4 days, the primary microorganisms of tobacco leaves entered a stable period, so the content of reducing sugar in tobacco leaves decreased less slowly than before. In addition to glucose and glutamate, cellulose degrading strain $\mathrm{C} 1$ was added in treatment 4, so its sugar consumption rate was higher than that in treatment 2, resulting in a continuous decrease of reducing sugar content. In the process of cigar wrapper leaves fermentation, part of soluble sugar is used as a carbon source for growth and development by microorganisms, and the other part reacts with alcohols and polyphenols to produce glycosides, which release aroma substances through pyrolysis (Mo 2017; Niu et al. 2020). In the process of cigar wrapper leaves fermentation, the change of total sugar content of tobacco leaf was basically consistent with that of reducing sugar (Fig. 5b). The research shows that the reduction of total sugar in the process of cigar wrapper leaves fermentation is conducive to improving the aroma of tobacco, and the smoking quality has a strong correlation with the content of total sugar and reducing sugar of tobacco (Liu et al. 2016; $\mathrm{Xu}$ 2016).

It can be seen from Fig. 5C that the total nitrogen content of cigar wrapper leaves did not change significantly during the fermentation process. A small amount of nitrogen source was added to the cigar wrapper leaves in control 2 and treatment 4 during the fermentation, but there was no significant difference in the total nitrogen content of the four treatments at the end of the fermentation, which was about $3.06 \%$. According to the analysis of Fig. 5D, nicotine fluctuated during the fermentation process, but the change was not obvious before and after fermentation, and the content was about $0.90 \%$, which was consistent with the research results before by $\mathrm{Xu}$ (2016). It was shown that the contents of total sugar, reducing sugar, nicotine, and total nitrogen after cigar fermentation were $0.41 \%, 0.04 \%, 1.41 \%$, and $3.91 \%$ respectively (Guo et al. 2021), which was similar to the present study. 

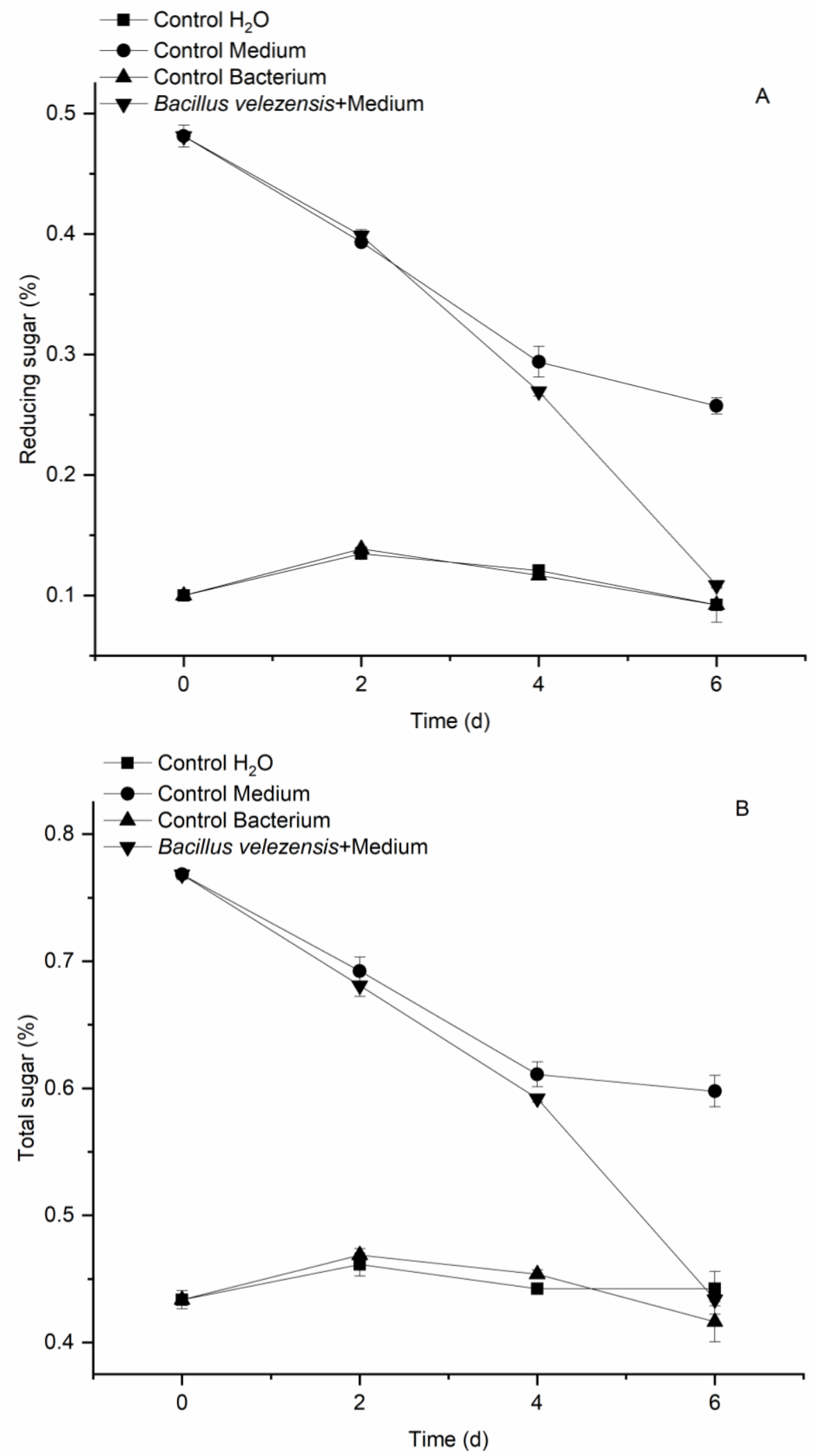

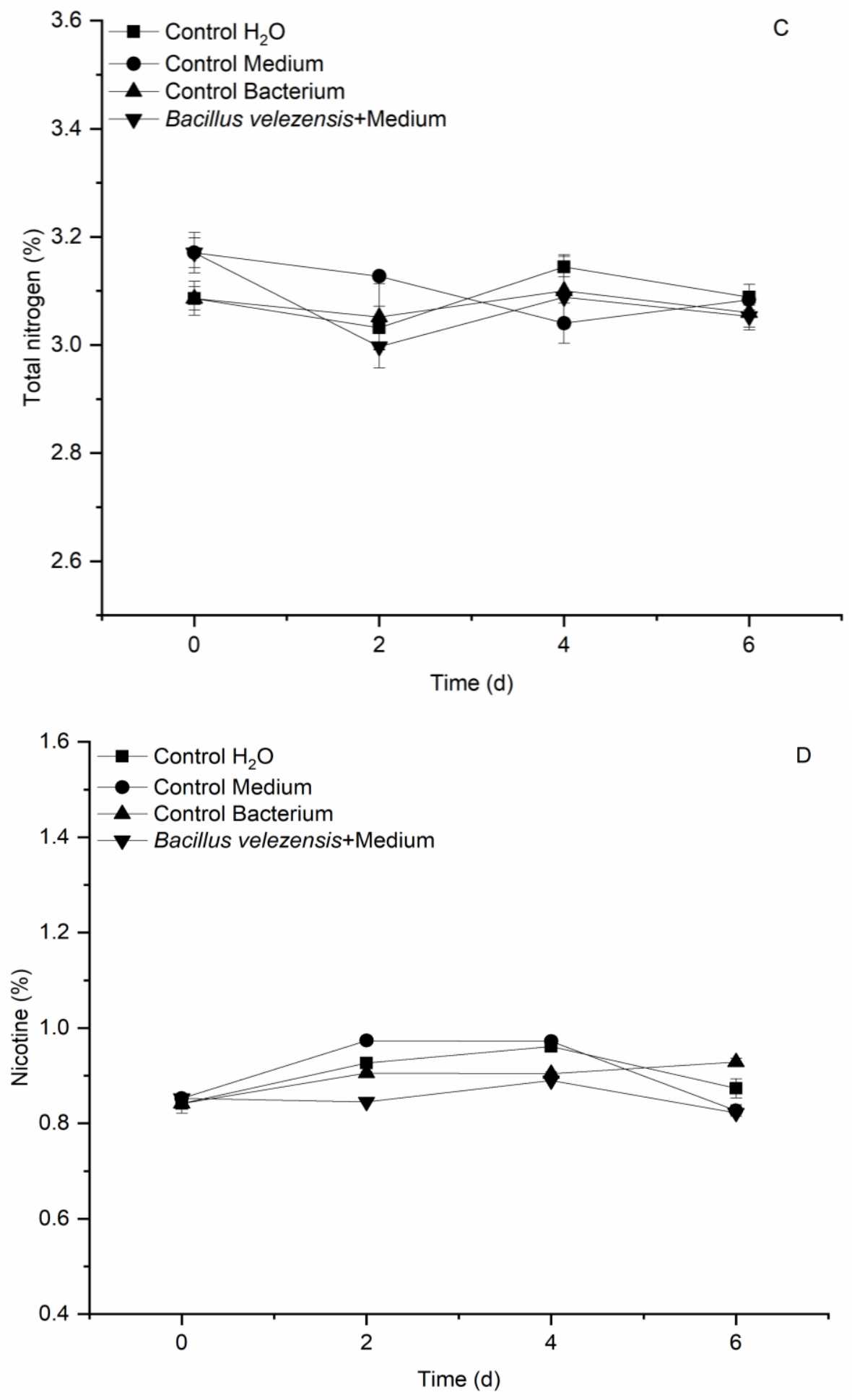

Fig. 5. Changes of chemical composition in cigar wrapper leaves during fermentation

\section{Volatile aroma compounds}

Aroma is one of the criteria to evaluate the quality of tobacco leaves. According to different extraction methods, aroma substances can be divided into acidic aroma substances, neutral aroma substances, and alkaline aroma substances (Chen et al. 2011). Acidic aroma substances include volatile acidic aroma substances and non-volatile acidic 
aroma substances. Most of the alkaline aroma components are nitrogen heterocyclic compounds. The main neutral aroma components include five categories: carotenoid degradation products, Siberian degradation products, aromatic amino acid metabolites, Maillard products, and neophytodienes. They are the most important aroma components in tobacco and have an important impact on cigarette quality and flavor style (Lu et al. 2012). Each of the neutral aroma components has different aroma characteristics, which has the greatest impact on the aroma quality, quantity and aroma type of tobacco leaves. On the other hand, acidic aroma components and alkaline aroma components have no obvious direct effect on the aroma of tobacco (Pan 2016). In recent years, studies in China and abroad have shown that substance with fragrance characteristics from tobacco leaves or smoke is mainly neutral aroma components (Yang et al. 2020), which is the focus of most related studies (Lu et al. 2012; Shi et al. 2013; Mo et al. 2017; Guo et al. 2021; Li et al. 2022). The aroma quantity and quality of tobacco leaves are determined by the composition and content of aroma components. Previous results showed that the increase of aroma substances in tobacco leaves can make the aroma softer, the smoke more delicate, and the taste more coordinated (Shi et al. 2013; Xun et al. 2019).

The analysis results of simultaneous distillation extraction and GC-MS are shown in Table 6. A total of 22 neutral aroma substances were detected, including 2 Maillard reaction products, 3 phenylalanine conversion products, 6 carotenoid conversion products, 1 cembranes conversion product, and 10 other types of aroma substances. In cigar wrapper leaves, the highest content of aroma substances was neophytodiene, followed by phytoalcohol, solanone, and phytoketone. These components play vital roles in producing fragrances and increasing the concentration of tobacco smoke ( $\mathrm{Li}$ et al. 2020a). Neophytodiene is considered as one of the key ingredients that contributed the most to the aroma of tobacco. It not only can effectively reduce irritants and soften the smoke, but also enhance aroma (Li et al. 2020a; Qin et al. 2020). Fitone, solanone, and phytol have floral, sweet, and jasmine aroma respectively, which can improve the aroma quality of cigar wrapper leaves.

In order to determine the effect of Bacillus velezensis $\mathrm{C} 1$ on the formation of aroma substances in cigar wrapper leaves, three groups of control experiments were carried out, i.e., sterile water treatment, $4.5 \%$ glucose and $2.25 \%$ glutamate treatment, treatment of mixed sterile water, and Bacillus velezensis $\mathrm{C} 1$. As shown in Fig. 5, compared with cigar wrapper leaves before fermentation, the total content of aroma substances after fermentation in the other four treatments increased significantly, and the total amount of aroma substances under the optimal fermentation process (No. 5) increased by $26.1 \%$ compared with that before fermentation. After fermentation, the content of carotenoid conversion products was higher than others (32 to $63 \mu \mathrm{g} / \mathrm{g}$ ), followed by cembranes conversion products (20 to $30 \mu \mathrm{g} / \mathrm{g}$ ) and phenylalanine conversion products ( 7.5 to 14 $\mu \mathrm{g} / \mathrm{g}$ ), and the content of Maillard reaction products was the lowest (3.4 to $6.3 \mu \mathrm{g} / \mathrm{g}$ ) (Fig. 6). During the fermentation process, a series of biochemical reactions happen in tobacco leaves (Zhang et al. 2021). The diversity and abundance of microbial community change dynamically, which produces a variety of hydrolases, including protease, pectinase, amylase, etc. Microorganisms cooperate with enzymes to transform polymers (carbohydrate and protein) in tobacco leaves into a series of small molecular aroma compounds (Li et al. 2019b; Du et al. 2016; Kou et al. 2011), which results increase of the volatile neutral aroma substances.

Maillard reactions are a non-enzymatic reaction between amino groups on protein, peptides, and amino acids with carbonyl groups of carbohydrates (Fu et al. 2019). Maillard 
reactions contribute to flavor, color, aroma, and taste, in addition to the bioactive properties of foods (Lund and Ray 2017). Maillard reaction is a source of beneficial flavours for cooked dairy products (Newton et al. 2012). Bitter taste of protein hydrolysates could be reduced by Maillard reaction (Abdelhedi et al. 2017). In addition, sweet, cocoa-like and milk powder-like aroma was intensified by Maillard reaction (Arsa and Theerakulkait 2015). It could also enhance the biological characteristics and antioxidant activity of milk proteins (Oh et al. 2013). Based on the principle of Maillard reaction, the extraction of tobacco powder was analyzed. It was found that Maillard reaction could effectively reduce the adverse components in the extraction and increase the flavor aroma components, such as furfural, megastigmatrienone, other aldehydes and ketones (Zhang et al. 2016). The Maillard reactions product contains many pleasant aromas, which has a significant impact on the taste when smoking and is beneficial to the formation of cocoa aroma (Zhang et al. 2020). The aroma substances produced by Maillard reaction included acids and carbonyl compounds, pyrrole, pyrazine derivatives, and pyridine. It can be seen from the results in Table 6 that the total amount of such substances before fermentation was only $1.33 \mu \mathrm{g} / \mathrm{g}$, and it was increased by various extents after fermentation. The content of Maillard reaction products in treatments 3 and 5 was higher than the others, with a total amount of $6.32 \mu \mathrm{g} / \mathrm{g}$ and $6.10 \mu \mathrm{g} / \mathrm{g}$, respectively. The content of furfuryl alcohol in treatment 5 was 4.5 times higher than that before fermentation (Fig. 7), which may be because the Maillard reaction was a polymerization reaction between amino compounds and reducing sugars, and the glucose and glutamate sources added in treatments 3 and 5 just met the needs.

Phenylalanine degradation products include benzyl alcohol, phenethyl alcohol, benzaldehyde, phenylacetaldehyde, and other components, which have a good impact on the aroma of tobacco. Phenylalanine conversion products can make the fragrance of flowers and fruits more prominent in fume. Before fermentation, the phenylalanine conversion product in cigar wrapper leaves was $4.06 \mu \mathrm{g} / \mathrm{g}$. After fermentation, it was increased to $13.7 \mu \mathrm{g} / \mathrm{g}$ and $11.4 \mu \mathrm{g} / \mathrm{g}$ in treatments 4 and 5, respectively. It was about two times higher than that of cigar wrapper leaves before fermentation, in which the contents of benzyl alcohol and phenylalcohol increased significantly (Fig. 7). Benzyl alcohol has a weak flower fragrance, while phenylethanol has a sweet and nutty fragrance. Benzyl alcohol and phenylethanol are important aroma components in tobacco leaves, which can enrich the aroma of tobacco leaves and improve the smoking quality of tobacco leaves.

Carotenoids are important aroma precursors in tobacco leaves, and their degradation products affect the aroma quality of tobacco leaves to a great extent. $\beta$ damascenone has the characteristic aroma of rose. Geranylacetone has a green flavor, which can increase the concentration of flue gas. Megastigmatrienone can increase the floral and woody aroma in tobacco leaves, and farnesylacetone has a sweet flavor and a green flue-cured tobacco flavor. The threshold of these aroma components is relatively low, and the contribution of them to flue gas aroma is huge. After fermentation by Bacillus velezensis $\mathrm{C} 1$, the content of carotenoid transformation products in cigar wrapper leaves was about twice as high than that of control 1, 2, and 3 (Fig. 7). Among them, the contents of $\beta$-damascenone, megastigmatrienone, and farnesyl acetone were significantly increased. These substances have a unique flower fragrance, which can not only greatly improve the aroma quality and aroma concentration of tobacco leaves, but also remove the impurities of tobacco leaves and make the aroma of tobacco leaves more coordinated (Li et al. 2008). Carotenoid transformation products were mainly ketones. The increase of ketones may be due to the conversion of some alcohols into ketones by Bacillus, or the enzyme secreted by Bacillus promotes the degradation of carotenoids in tobacco leaves to beta-damascenone 
and megastigmatrienone (Shuai et al. 2020; Xu et al. 2012).

A variety of aroma substances are produced during the degradation of cembranes substances, among which solanone has an important impact on the smoking quality of tobacco leaves. The main cembrane-like compound in tobacco is 2,6,11-cembratriene-4,8diol. Its degradation product, solanone, is one of the important aroma substances in tobacco. Solanone itself has good fragrance and can be used as an important monomer fragrance. It can be seen in Table 6 that the content of solanone increased significantly from 21.6 to $36.1 \mu \mathrm{g} / \mathrm{g}$ after fermentation of cigar wrapper leaves with Bacillus velezensis $\mathrm{C} 1$ (Fig. 7), indicating that Bacillus velezensis $\mathrm{C} 1$ has a great contribution to the transformation of cembranes substances. Neophydiene was the highest content of neutral aroma substances in cigar wrapper leaves. It has no obvious aroma, but as a precursor it can be further transformed into other aroma substances to make the aroma of tobacco leaves more coordinated. Table 6 shows that the content of neophydiene in treatment 5 was 249 $\mu \mathrm{g} / \mathrm{g}$ after fermentation, the highest among all the treatments.

Table 6. Changes of Volatile Neutral Aroma Components in Cigar Wrapper Leaves After Fermentation

\begin{tabular}{|c|c|c|c|c|c|}
\hline Treatment & $\begin{array}{c}1 \\
(\mu g / g)\end{array}$ & $\begin{array}{c}2 \\
(\mu g / g)\end{array}$ & $\begin{array}{c}3 \\
(\mu g / g)\end{array}$ & $\begin{array}{c}4 \\
(\mu g / g)\end{array}$ & $\begin{array}{c}5 \\
(\mu g / g)\end{array}$ \\
\hline Furfural & 0.17 & - & 0.84 & - & - \\
\hline Furfuryl alcohol & 1.16 & 3.44 & 5.48 & 5.79 & 6.10 \\
\hline Browning reaction product & 1.33 & 3.44 & 6.32 & 5.79 & 6.10 \\
\hline Benzaldehyde & 0.55 & 0.47 & 0.42 & 0.54 & 0.65 \\
\hline Benzyl alcohol & 1.59 & 4.08 & 4.39 & 7.03 & 6.21 \\
\hline Phenethyl alcohol & 1.92 & 3.01 & 5.00 & 6.15 & 4.50 \\
\hline $\begin{array}{l}\text { Phenylalanine conversion } \\
\text { products }\end{array}$ & 4.06 & 7.56 & 9.81 & 13.72 & 11.36 \\
\hline $\begin{array}{c}\text { 2,6,6-Trimethyl-2- } \\
\text { cyclohexene-1,4-dione }\end{array}$ & 0.82 & 0.70 & 0.81 & 1.20 & 1.28 \\
\hline beta-Damascenone & 5.88 & 5.97 & 6.78 & 12.46 & 10.20 \\
\hline Geranylacetone & 3.17 & 1.80 & 2.28 & 3.62 & 3.58 \\
\hline Megastigmatrienone A & 4.78 & 7.56 & 7.78 & 13.75 & 14.97 \\
\hline Megastigmatrienone B & 5.63 & 8.22 & 9.61 & 15.24 & 14.92 \\
\hline Farnesyl acetone & 7.77 & 8.62 & 12.47 & 16.12 & 18.15 \\
\hline Carotenoid products & 28.05 & 32.87 & 39.73 & 62.39 & 63.10 \\
\hline Solanone & 21.65 & 19.85 & 26.51 & 36.09 & 30.15 \\
\hline $\begin{array}{c}\text { Cembranes conversion } \\
\text { products }\end{array}$ & 21.65 & 19.85 & 26.51 & 36.09 & 30.15 \\
\hline Trans-2-Hexenal & 0.37 & - & 0.55 & 0.49 & 0.82 \\
\hline 6-Methyl-5-hepten-2-one & 0.43 & 1.23 & 1.06 & 1.35 & 1.42 \\
\hline Trans,trans-2,4-Nonadienal & 0.61 & - & 0.40 & 0.47 & 0.52 \\
\hline 3-Acetylpyridine & 4.63 & - & 4.83 & 2.38 & 8.03 \\
\hline Beta-cyclocitral & - & 0.16 & 0.17 & 0.36 & 0.40 \\
\hline 4-Hydroxy-3-methoxystyrene & - & - & 2.16 & 2.86 & 5.32 \\
\hline Boronal & 3.40 & 1.83 & 3.02 & 3.50 & 6.16 \\
\hline Fitone & 15.75 & 13.98 & 17.52 & 22.86 & 19.28 \\
\hline Phytol & 123.68 & 59.68 & 115.65 & 84.25 & 131.54 \\
\hline Neophytadiene & 219.19 & 160.84 & 202.45 & 231.358 & 249.26 \\
\hline $\begin{array}{c}\text { Total aroma (except } \\
\text { Neophytadiene,Phytol) }\end{array}$ & 80.28 & 80.92 & 112.08 & 152.26 & 152.66 \\
\hline Total & 423.15 & 301.44 & 430.18 & 467.87 & 533.46 \\
\hline
\end{tabular}

"_" means not detected. 
Figure 8 is the heat map made of main aroma substances in cigar wrapper leaves. It can be clearly seen from Fig. 8 that the contents of furfuryl alcohol, megastigmatrienone, farnesyl acetone, and 3-acetylpyridine in treatment 5 were significantly higher than those in other treatments, while the contents of benzyl alcohol, $\beta$-damascenone, and phytol in treatment 4 were higher than those in other treatments. After the fermentation of cigar wrapper leaves by Bacillus velezensis $\mathrm{C} 1$, the content of aroma substances in cigar wrapper leaves increased significantly, indicating that the fermentation by strain $\mathrm{C} 1$ plays an important role in improving the quality of cigar wrapper leaves.

The type and content of aroma substances in cigar wrapper leaves have a great impact on smoking quality, and the content of aroma substances in tobacco leaves has a significant positive correlation with sensory quality (Guo et al. 2019). After treating tobacco leaves with cellulase, it was found that the total amount of neutral aroma substances in tobacco leaves increased by $25.5 \%$ (Li et al. 2008). The total content of aroma components in the treated tobacco leaves by Bacillus, increased by $33.2 \%$ compared with the control (Xue et al. 2019). It was also found that adding Aroma Producing Strains during tobacco fermentation can significantly improve the content of aroma substances in tobacco leaves and improve the smoking quality of tobacco leaves, which is basically consistent with the results of the current study (Hu et al. 2020).

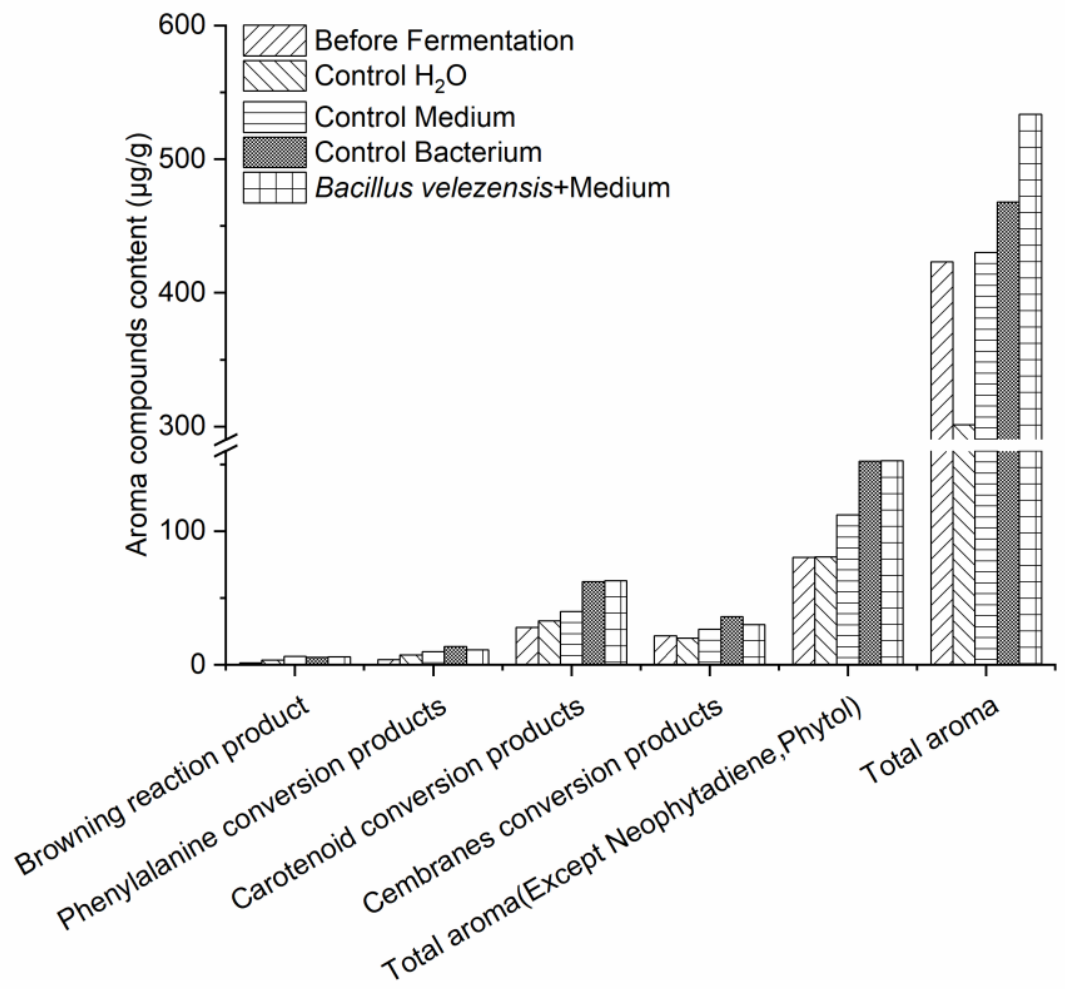

Fig. 6. The effect of different fermentation process on the amount of volatile neutral aroma components in cigar wrapper leaves 

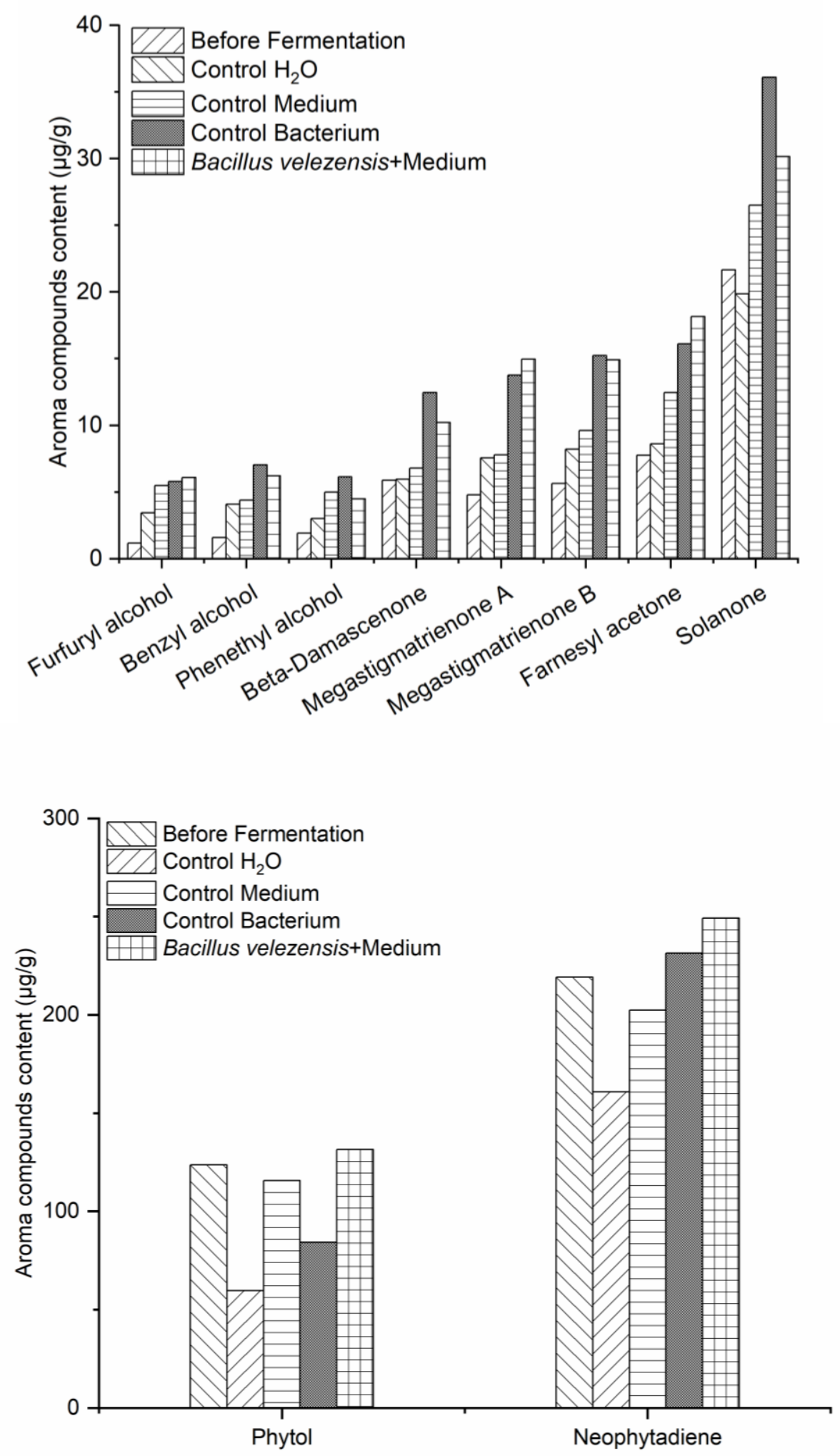

Fig. 7. The effect of different fermentation process on the amount of important volatile neutral aroma components in cigar wrapper leaves 


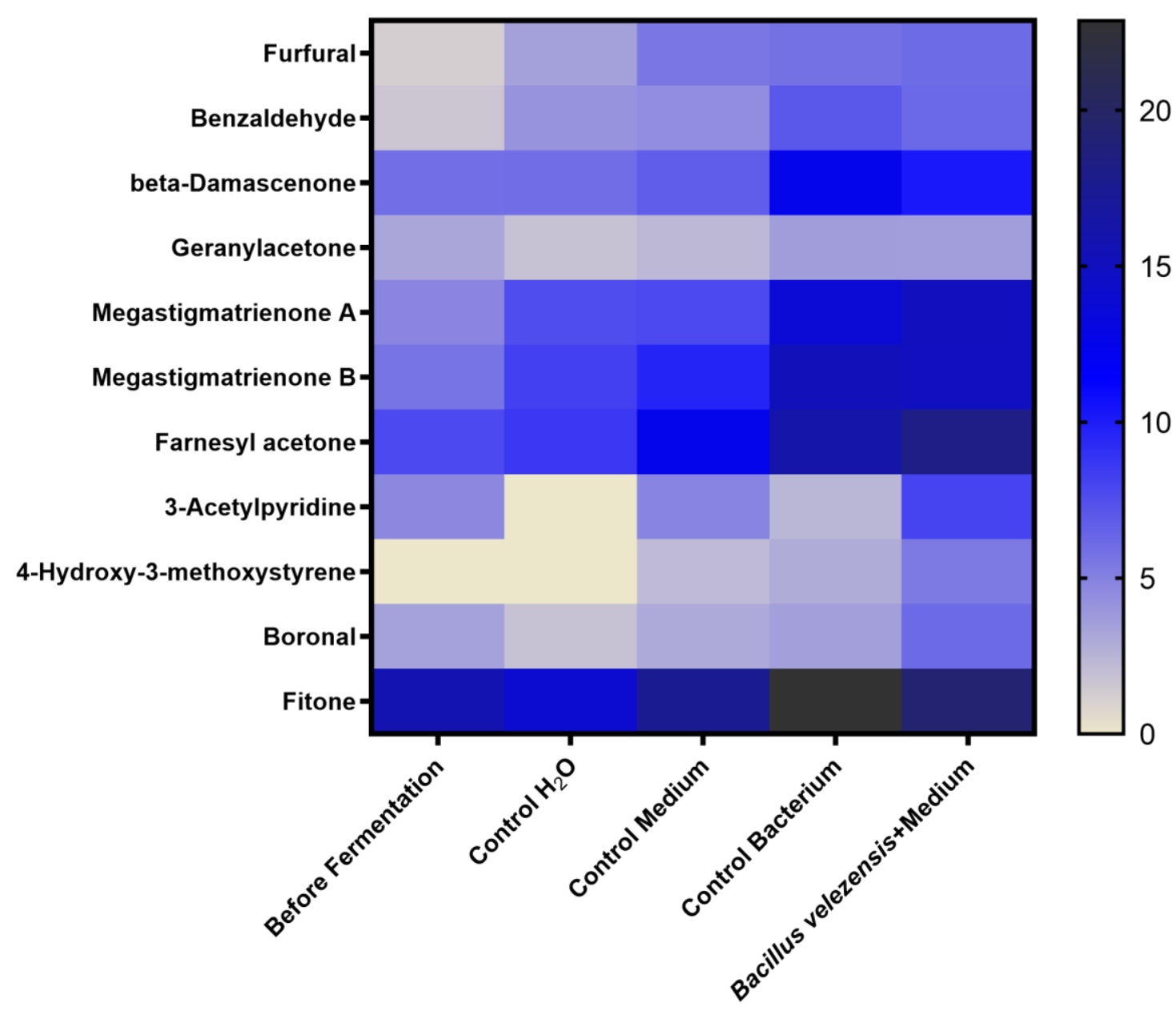

Fig. 8. Heat map of volatile neutral aroma components in cigar wrapper leaves after fermentation

\section{Changes of enzyme activity during cigar wrapper fermentation}

In order to elucidate the mechanism of Bacillus velezensis $\mathrm{C} 1$ on aroma substances production, the changes of protease, amylase, and cellulase activities during fermentation under the optimal process conditions were studied. The results are shown in Fig. 9. As can be seen from Fig. 9a, the protease activities of treatments 1, 3, and 4 generally showed a downward trend during the fermentation process, while treatment 2 basically was stable after 2 days of fermentation. The highest protease activity of $16.6 \mathrm{U} / \mathrm{g}$ was found at the beginning of fermentation. On the $6^{\text {th }}$ day, the protease activity was not significantly different among various treatments, which was between 10 to $14 \mathrm{U} / \mathrm{g}$.

Figure 9B shows that during the fermentation process, the amylase activity generally increased first and then decreased, in which the amylase activity of treatments 2 and 3 reached the maximum on the $2^{\text {nd }}$ day of fermentation. Treatment 4 reached the highest enzyme activity of $144.9 \mathrm{U} / \mathrm{g}$ on the $4^{\text {th }}$ day, and the activity decreased to $81.9 \mathrm{U} / \mathrm{g}$ on the $6^{\text {th }}$ day. The results indicated that amylase secreted by Bacillus velezensis $C 1$ was not the main contribution to the quality improvement of cigar wrapper leaves.

It was suggested from Fig. 9C that the cellulase activity of treatment 1 basically remained unchanged during the whole fermentation process, while the cellulase activity of treatments 2 and 3 slightly increased and then decreased during the fermentation process. 
In treatment 4 , the cellulase activity increased rapidly and reached the maximum value of $289 \mathrm{U} / \mathrm{g}$ on the $6^{\text {th }}$ day. This may be because in the early stage of fermentation, Bacillus velezensis $\mathrm{C} 1$ grew well with the exogenous added nutrients. With the process of fermentation, when the nutrients were insufficient, Bacillus velezensis $\mathrm{C} 1$ began to secrete cellulase, and cellulose was used as the carbon source. Therefore, it can be preliminarily concluded that the improvement of cigar wrapper leaves quality by Bacillus velezensis $\mathrm{C} 1$ was mainly achieved by cellulase production.
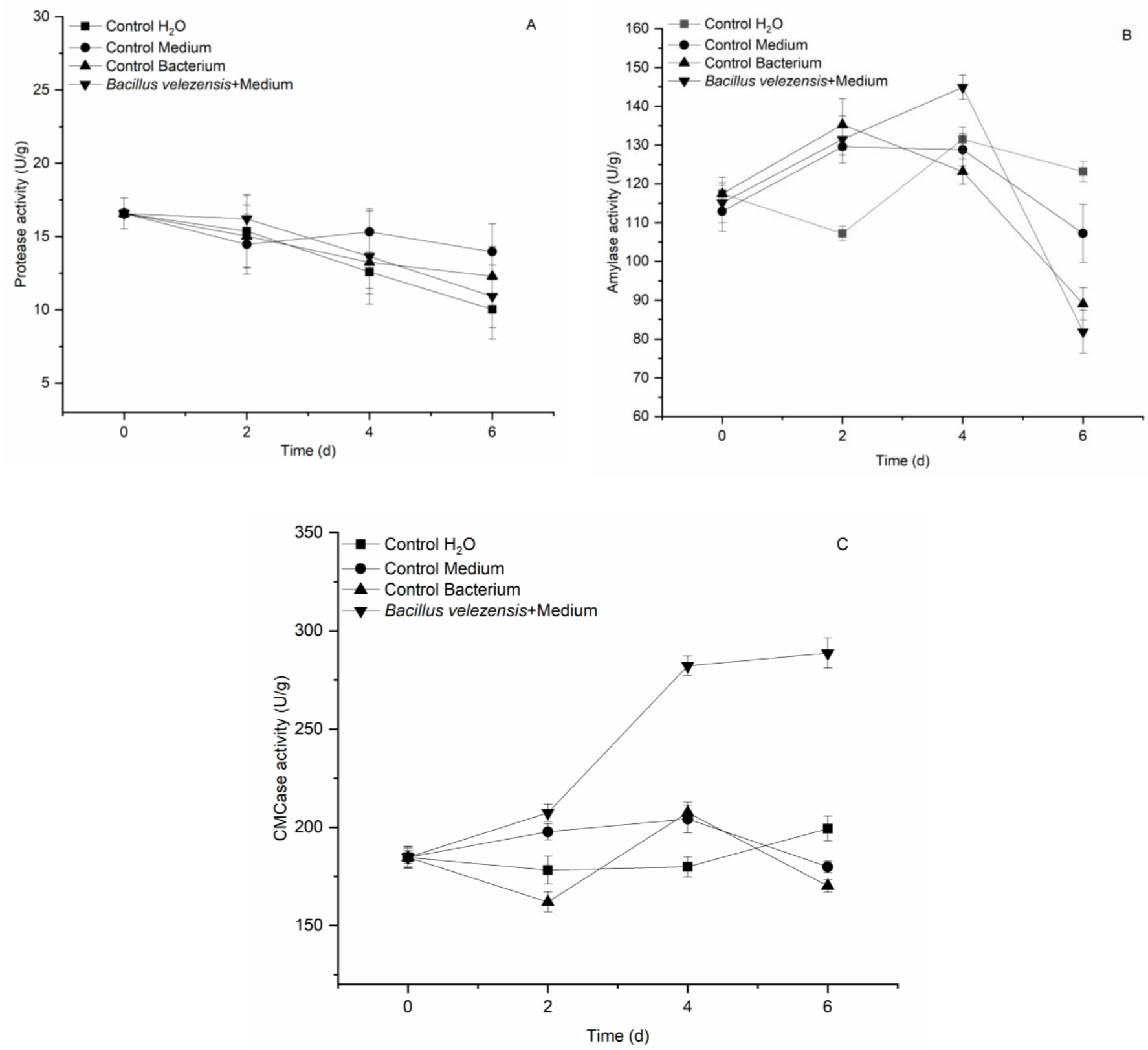

Fig. 9. Changes of enzyme activity in cigar wrapper leaves during fermentation 


\section{CONCLUSIONS}

1. In this study, a strain called $\mathrm{C} 1$ with high cellulase production ability was screened from cigar wrapper leaves in Enshi, Hubei Province, China.

2. After being cultured in enzyme producing medium, it was found that the highest CMC enzyme activity was at $44.3 \mathrm{U} / \mathrm{mL}$ in $24 \mathrm{~h}$. It was identified as Bacillus velezensis by molecular biology.

3. When the strain was mixed with a certain concentration of glucose and glutamate, it was sprayed on cigar wrapper leaves for fermentation. It was found that the cellulose content of tobacco leaves decreased significantly. At the optimum condition (inoculation concentration of $20 \%$, fermentation temperature of $37^{\circ} \mathrm{C}$, addition of $4.5 \%$ glucose and $2.25 \%$ glutamate), $31.7 \%$ of cellulose in tobacco leaves was degraded.

4. The total amount of aroma substances were increased by $26.1 \%$ compared with that before fermentation, in which $\beta$-damascenone, megastigmatrienone, farnesyl acetone, and solanone were significantly improved. It was indicated that fermentation of cigar wrapper leaves can significantly improve the aroma quality and reduce the miscellaneous gas of cigar wrapper leaves.

\section{ACKNOWLEDGMENTS}

The authors are grateful for the support from the National Natural Science Foundation of China (Grant No. 21978074 and 31871789), the Key Laboratory of Fermentation Engineering (Ministry of Education) (Grant No. 202105FE04), key project of Hubei Provincial Department of Education (D20211404), the China National Tobacco Corporation (Grant No. 110202001039(XJ-01)), and the Hubei Tobacco Corporation (Grant No. 027Y2019-003).

\section{REFERENCES CITED}

Abdelhedi, O., Mora, L., Jemil, I., Jridi, M., Toldra, F., Nasri, M., and Nasri, R. (2017). "Effect of ultrasound pretreatment and Maillard reaction on structure and antioxidant properties of ultrafiltrated smoothhound viscera proteins-sucrose conjugates," Food Chemistry 230, 507-515. DOI: 10.1016/j.foodchem.2017.03.053

Arsa, S., and Theerakulkait, C. (2015). "Sensory aroma characteristics of alcalas hydrolyzed rice bran protein concentrate as affected by spray drying and sugar addition," Journal of Food Science and Technology 52, 5285-5291. DOI: 10.1007/s13197-014-1610-5

Buntić, A. V., Milić, M. D., Stajković-Srbinović, O. S., Rasulić, N. V., Delić, D. I., and Mihajlovski, K. R. (2019). "Cellulase production by Sinorhizobium meliloti strain 224 using waste tobacco as substrate," International Journal of Environmental Science and Technology 16(10), 5881-5890. DOI: 10.1007/s13762-019-02230-9

Chen, S., Li, W., Li, C., and Ke, Y. (2011). "Effects of nitrogen amounts on acid and alkali aroma substance content in flue-cured tobacco," Chinese Agricultural Science Bulletin 27, 367-372. 
Chen, X., Wang W., Wang X., Dang, L., Zhao, Y., Yan, K., Lin, J., Duan, Y. (2015). "Screening and identification of tobacco cellulose degradation bacteria and optimization of enzyme production conditions," Journal of Yunnan University 37(2), 323-328. DOI: 10.7540 /j.ynu.20140343

Dai, J. (2012). Study on Bacterial Resource in the Districts of Xinjiang-Tibet and the Primary Analysis of Whole Genome Sequence of Pontibacter korlensis X14-1T, Ph.D. Dissertation, Wuhan University, Wuhan, China.

Dong, J. (2011). Improvement of Cellulase Productivity of Penicillium decumbens by Ion Beam Implantation and Genome Shuffling and Application of the Cellulase, Master's Dissertation, Shangdong University, Jinan, China.

Du, J., Zhang, X., Wu, G., Zhou, R., Cui, Y., and Shi, X. (2016). "Studies on leaf surface microflora of cigar-wrapper during artificial fermentation," Current Biotechnology 6(3), 188-192. DOI: 10.3969/j.issn.2095-2341.2016.03.07

Fu, Y., Zhang, Y., Soladoye, O., and Aluko, R. (2019). "Maillard reaction products derived from food protein-derived peptides: insights into flavor and bioactivity," Critical Reviews in Food Science and Nutrition 60, 3429-3442. DOI: 10.1080/10408398.2019.1691500

Guo, H., Zhang, Y., Li, Y., and Xu, K. (2019). "Study on the correlation between volatile aroma substances and sensory quality of cigarettes," Food and Machinery 35, 209212. DOI: 10.13652/ j.issn.1003-5788.2019.01.037

Guo, W., Ding, S., Liu, L., Zhong, Q., Liu, Y., Hu, X., Ye, K., Wang, J., Lu, R., and Shi, X. (2021). "Effects of pile turning on the quality change of cigar core tobacco leaf during primary fermentation," Journal of Southern Agriculture 52, 365-373. DOI: 10.3969/j.issn.2095-1191.2021.02.012

Hu, T., Jiao, K., Huang, Q., Wu, S., Hou, N., Li, M., and Ma, L. (2020). "Screening of solid-state fermentation aroma-producing strains," Farm Products Processing 4(8), 52-58. DOI: 10.16693/j.cnki.1671-9646(X).2020.04.046

Kou, M., Wang, C., Dai, Y., Zeng, D., Feng, G., Zhang, Y., Liu, L., Yang, W., Li, N., Wu, Y., Zhao, M., Jia, Y., and Lei, J. (2011). "Effect of protease treatment on the quality of cigar content," Journal of Southwest University (Natural Science) 33, 149153. DOI: 10.13718/j.cnki.xdzk.2011.10.016

Li, G., Ma, H., Yu, J., Yang, H., and Dong, G. (2008). "Effect on using cellulase to degradate cellulose in hue-cured tobacco," Chinese Agricultural Science Bulletin 4, 256-259.

Li, H., Bai, G., Lan, N., Xu, J., Zhao, X., and Zou, W. (2019a). "Screening and identification of a cellulase-producing bacterium and analysis of its cellulase characterization," China Animal Husbandry and Veterinary Medicine 46(3), 711-718. DOI: 10.16431/j.cnki.1671-7236.2019.03.009

Li, X., Li, M., Wan, D., Li, L., Chen, D., Ding, S., and Shi, X. (2019b). "Role of microorganisms in tobacco fermentation and alcoholization: A review," Microbiology China 46, 1520-1529. DOI: 10.13344/j.microbiol.china.180580

Li, J., Zhao, Y., Qin, Y., and Shi, H. (2020a). "Influence of microbiota and metabolites on the quality of tobacco during fermentation," BMC Microbiology 20, Article number 356. DOI: 10.1186/s12866-020-02035-8

Li, Z., Zhu, J., Tang, L., Dong, G., Wu, T., Liao, T., Zhang, W., Xia, Y., Wang, Y., and Li, Y. (2020b). "Isolation, identification and cellulase enzyme activity determination of cellulase-producing bacteria from tobacco straw," Southwest China Journal of Agricultural Sciences 33(3), 645-650. DOI: 10.16213/j.cnki.scjas.2020.3.027 
Li, Z., Zhang, G., Mo, Z., Deng, S., Li, J., Zhang, H., Liu, X., and Liu, H. (2022). "Effects of a xylanase-producing Bacillus cereus on the composition and fermented products of cigar leaves," Biotechnology Bulletin 38, 24-31. DOI:

10.13560/j.cnki.biotech.bull.1985.2021-0349

Liang, Q., Li, H., and Wang, Z. (2019). "Isolation and identification of cellulaseproducing strains and characterization of their cellulases," Journal Guangdong Pharmaceutical University 35(1), 120-125. DOI: 10.16809/j.cnki.20963653.2018110503

Liu, X., Meng, L., Liang, M., Wang, C., Song, W., Zheng, J., and Xu, Y. (2015a). "Correlations between quality index and content of cellulose and lignin in upper leaves of flue-cured tobacco in Wulin mountain area," Agricultural Science and Technology 31(10), 2135-2140. DOI: 10.16175/j.cnki.1009-4229.2015.10.014

Liu, Y., Gao, W., Chen, S., Wang, J., and Fan, J. (2015b). “Optimization of fermentation conditions for cellulase production by B. pumilus isolated from tobacco surface," Journal of Anhui Agricultural Sciences 43, 306-309. DOI: 10.13989/j.cnki.05176611.2015 .17 .086

Liu, Z., Tuo, Y., Ma, C., Wang, Q., Yu, C., and Zhang, Y. (2016). “Correlations between chemical components and sensory smoking quality of re-drying flue-cured tobacco from different producing areas," Guizhou Agricultural Sciences 44(7), 113-116.

Lu, C., Chen, J., Wang, Y., Zhan, P., and Zhang, L. (2012). "Screening and identification of a cellulase-producing fungus and optimization of its fermentation conditions," Journal of Central South University For Technology 32, 118-127. DOI: 10.14067/j.cnki.1673-923x.2012.06.005

Lu, L. (2012). Identification and evaluation of characteristic flavor compounds in Fenflavor Cigarette, Master's Dissertation, Jiangnan University, Wuxi, China.

Lund, M., and Ray, C. (2017). "Control of Maillard reactions in foods: Strategies and chemical mechanisms," Journal of Agricultural Food and Chemistry 65, 4537-4552. DOI: $10.1021 /$ acs.jafc.7b00882

Mo, J. (2017). Study on the Changes of the Routine Chemical Composition and Neutral Aroma Components in the Process of Fermentation of Maduro Cigar WrapperLeaves, Master's Dissertation, Henan Agricultural University, Zhengzhou, China.

Newton, A., Fairbanks, A., Golding, M., and Paul, G. J. (2012). "The role of the Maillard reaction in the formation of flavour compounds in dairy products-not only a deleterious reaction but also a rich source of flavour compounds," Food and Function 3, 1231-1241. DOI: 10.1039/c2fo30089c

Ni, H., Ma, Y., Lin, L., Ji, X., Wang, Y., and Wei, Y. (2012). "Degrading starch and cellulose in tobacco leaves by bacteria enzyme agents isolated from Yuxi tobacco leaf surface," J. Agric. Biotechnol. 20(3), 268-274. DOI: 10.3969/j.issn.16747968.2012.03.006

Niu, H., Zhou, Z., Bai, J., Zhang, M., Sun, Z., and Chen, E. (2020). "Research progress of cigar fermentation," Journal of Hunan University Natural Sciences 32, 60-68. DOI: 10.3969/j.issn.1672-6146.2020.04.012

Oh, N., Lee, H., Lee, J., Joung, J., Lee, K., Kim, Y., Lee, K., and Kim, S. (2013). “The dual effects of Maillard reaction and enzymatic hydrolysis on the antioxidant activity of milk proteins," Journal of Dairy Science 96, 4899-4911. DOI: 10.3168/jds.20136613

Pan, L. (2016). The Relationship between neutral aroma components and Physical and Chemical characteristic and ecological factors of flue cured tobacco in Hubei 
Province, Master's Dissertation, Hubei University, Wuhan, China. •

$\mathrm{Pu}$, J., and Liu, Y. (2019). "The correlation between the content of cellulose in cured tobacco and the quality of tobacco leaves," Agricultural Science and Engineering in China 31(2), 67-70. DOI: 10.3969/j.issn.1002-5103.2019.02.019

Qin, M., Chen, S., Zhao, Q., Peng, C., Jin, B., and Tao, H. (2020). “Application of Lactobacillus plantarum in improving the quality of tobacco leaves from different regions," Food and Machinery 36, 199-226. DOI: 10.13652/j.issn.10035788.2020.05.037

SB/T 10317-1999 (1991). "Measurement of proteinase activity," Standardization Administration of China, Beijing, China.

Shi, X., Wang, X., Lin, K., Cui, J., Li, Z., and Li, L. (2013). "Changes of aroma substances in cigar wrapper tobacco leaves during the stacking fermentation," Acta Agriculturae Boreali-Occidentalis Sinica 22, 118-123.

Shi, X., Zhang, X., Wang, W., Gu, H., Zeng, D., and Fu, L. (2006). "Changes of aroma substances in cigar-wrapper tobacco leaves during artificial fermentation," China Tobacco Science 27(1), 1-4. DOI: 10.13496/j.issn.1007-5119.2006.01.001

Shuai, Y., Tao, H., Tian, Y., Tian, Y., Cheng, K., and He, L. (2020). "Changes of enzyme production and volatile flavor compounds in tobacco leaves fermented by mixed starter," Journal of Henan Agricultural Sciences 49, 162-175. DOI: 10.15933/j.cnki.1004-3268.2020.10.023

Wang, W., Xue, Q., and Du, L. (2012). "Effect of Bacillus subtilis producing cellulase on the cellulose and soluble sugar content of tobacco leaf," Journal of Anhui Agricultural Science 30, 14937-14939. DOI: 10.13989/j.cnki.0517-6611.2012.30.229

Wang, Y., Ma, L., Lv. X., Zhao, D., and Huang, Z. (2015). "Effects of single and mixed culture solid state fermentation on main chemical components in cigarette clend," Tobacco Science and Technology 48, 47-52. DOI: 10.16135/j.issn10020861.20151109

Wang, J., Chen, Y., Li, M., and Kurban, A. (2019). "Screening, identification of a coldactive cellulase strain and characterization of its cellulose production," Acta Agriculturae Universitatis Jiangxiensis 41(2), 356-364. DOI: 10.13836/j.jjau.2019043

Xiao, Z., Storms, R., and Tsang, A. (2006). "A quantitative starch-iodine method for measuring alpha-amylase and glucoamylase activities," Analytical Biochemistry 351(1), 146-148. DOI: 10.1016/j.ab.2006.01.036

$\mathrm{Xu}, \mathrm{C}$., Wang, Z., Zheng, J., and Mao, D. (2012). "A review on the degradation of carotenoids," Journal of Zhengzhou Institute of Light Industry (Natural Science Edition) 27, 56-59. DOI: 10.3969 /j.issn.1004-1478.2012.04.015

$\mathrm{Xu}, \mathrm{S}$. (2016). Effects of Different Materials Handling to the Quality of Hainan Cigarwrapper During the Initial Artificial Fermentation, Master's Dissertation, Henan Agricultural University, Zhengzhou, China.

Xue, L., Zheng, Z., Guo, Z., Wang, Y., Guo, B., Chen, W., Jiang, Y., and Lai, H. (2019). "Screening and application of aroma-enhancing bacteria for tobacco," Chin. Tob. Sci. 40, 60-67. DOI: 10.13496/j.issn.1007-5119.2019.05.009

Yang, Y., Peng, Q., Ou, M., Wu, Y., and Fang, J. (2018a). "Research progress in tobacco fermentation," Journal of Biosciences and Medicines 6(6), 105-114. DOI: 10.4236/jbm.2018.66008

Yang, Z., Feng, Y., Li, L., Zhang, Y., Li, J., and Liu, C. (2018b). "Study on screening and application of an efficient cellulose-degrading strain from tobacco leaf," Journal 
of Henan Agricultural University 52, 418-423. DOI: 10.16445/j.cnki.10002340.2018.03.018

Yang, J., Song, M., Yang, P., He, C., Zhong, W., Jia, C., and Mao, D. (2020). “Analysis of fresh (green) aroma note of flue-cured tobacco based on odor activity value," Tobacco Science and Technology 53, 34-43. DOI: 10.16135/j.issn10020861.2019 .0132

Yao, F. (2017). Identification Microbiological on Hainan Cigar Wrapper Leaves and Its Effect During Artificial Fermentation on the Chemical Composition of Cigar Wrapper, Master's Dissertation, Henan Agricultural University, Zhengzhou, China.

YC/T 159-2002 (2002). "Tobacco and tobacco products-Determination of water soluble sugars - Continuous flow method," Standardization Administration of China, Beijing, China.

YC/T 160-2002 (2002). "Tobacco and tobacco products - Determination of total alkaloids-Continuous flow method," Standardization Administration of China, Beijing, China.

YC/T 161-2002 (2002). "Tobacco and tobacco products - Determination of total nitrogen - Continuous flow method," Standardization Administration of China, Beijing, China.

YC/T 31-1996 (1996). "Tobacco and tobacco products - Preparation of test sample and determination of water content - Oven method," Standardization Administration of China, Beijing, China.

Yu, S., Mao, S., Hu, A., Zhu, H., Kong, L., and Bie, X. (2021). "Study on screening of microorganisms for improving tobacco leaf quality and their effects," Journal of Nanjing Agricultural University 44, 766-777. DOI: 10.7685 /jnau.202011008

Zeng, W., Xu, L., Jiang, J., Zhang, J., Zhang, T., Li, X., and Xiang, H. (2020). "Screening of the aroma-producing strain and analysis of its aroma production characteristics," Genomics and Applied Biology 39, 636-643. DOI: 10.13417/j.gab.039.000636

Zhang, C., Xu, G., and Yan, X. (2012). "Improve the aroma characteristics of the tobacco extracts by Saccharomyces cerevisiae," Science and Technology of Food Industry 33, 137-141. DOI: 10.13386/j.issn1002-0306.2012.20.053

Zhang, P., Yu, J., Long D., Li, Z., and Zhang, X. (2016). “Application of Maillard reaction to improve the quality of tobacco sheets," Food and Machinery 32, 39-44. DOI: 10.13652/j.issn.1003-5788.2016.03.008

Zhang, R., Su, Q., Yang, C., and Chen, F. (2020). "Effect of stacking fermentation time on quality of Wuzhishan cigar wrapper tobacco leaves," Shandong Agricultural Sciences 52(4), 57-61. DOI: 10.14083/j.issn.1001-4942.2020.04.010

Zhang, L., Luo, Z., Yang, M., Li, S., Xin, Y., Cai, B., Liu, H., Ceng, D., Gu, J., and Duan, B. (2021). "Diversity of fermentation microbes and changes of hydrolytic enzyme activities of cigar leaf raw materials," Journal of Agricultural Science and Technology 23, 171-180. DOI: 10.13304/j.nykjdb.2020.0534

Zhou, J., Yu, L., Zhang, J., Zhang, X., Hu, D., Ou, M., and Zou, X. (2018). "Study on the characteristics of bacterial community succession in tobacco aging," Acta Ecol. Sin. 8, 7739-7748. DOI: 10.5846 /stxb201710161857

Article submitted: November 1, 2021; Peer review completed: December 19, 2021; Revised version received and accepted: December 31, 2021; Published: January 14, 2022. DOI: 10.15376/biores.17.1.1566-1590 